Assessment of in vivo estrogenic and anti-inflammatory activities of the hydro-ethanolic extract and polyphenolic fraction of parsley (Petroselinum sativum Hoffm.)

\title{
Slighoua, Meryem
}

2021-01-30

Slighoua , M , Mahdi , I , Amrati , F E-Z, Di Cristo , F , Amaghnouje , A, Grafov , A , Boucetta , N , Bari , A \& Bousta , D 2021, ' Assessment of in vivo estrogenic and anti-inflammatory activities of the hydro-ethanolic extract and polyphenolic fraction of parsley (Petroselinum sativum Hoffm.) ' , Journal of Ethnopharmacology , vol. 265 , 113290 . https://doi.org/10.1016/j.jep.20

http://hdl.handle.net/10138/340843

https://doi.org/10.1016/j.jep.2020.113290

cc_by_nc_nd

acceptedVersion

Downloaded from Helda, University of Helsinki institutional repository.

This is an electronic reprint of the original article.

This reprint may differ from the original in pagination and typographic detail.

Please cite the original version. 


\title{
Manuscript Details
}

\section{Manuscript number}

Title
JEP_2020_1053

Assessment of in vivo estrogenic and anti-inflammatory activities of the hydroethanolic extract and polyphenolic fraction of Parsley (Petroselinum sativum)

\begin{abstract}
Ethnopharmacological relevance: since the dawn of time, medicinal and aromatic plants (AMPs) represent a precious heritage for humanity, especially in developing countries, who exploit their virtues in traditional pharmacopoeia to cope with health problems such as diabetes, kidney stones, ulcer, and digestive disorders. Petroselinum sativum belongs to family Apiaceae. It is traditionally used to treat arterial hypertension, diabetes, cardiac disease, renal disease, and recently reported as a plant endowed a female fertilizing effect. Aim of the study: This study aims to evaluate the in vivo effect of hydro-ethanolic extract of Petroselinum sativum and polyphenols on cholesterol, protein and estrogen levels, and characterize the chemical composition of polyphenolic fraction. In addition, acute toxicity and antiinflammatory activity of tested extract was also investigated. Materials and Methods: Chemical composition of polyphenolic fraction was determined using High-Performance Liquid Chromatography with Diode-Array Detection (HPLC-DAD). First, toxicological investigations including sub-acute toxicity were performed by measuring animals' weights daily for four weeks. Afterwards, histopathological examination of livers and kidneys, and serum assay of ASAT, and ALAT were also checked. Next, the acute in vivo anti-inflammatory study of the hydro-ethanolic extract of Petroselinum sativum and polyphenols versus Indomethacin was conducted. Furthermore, we evaluated the estrogenic effect of its hydro-ethanolic extract and the polyphenolic fraction following biochemical assays for the determination of proteins, cholesterol and estrogen levels. Results: The results revealed the presence of some phenolic compounds mainly Ferulic acid, gallic acid and quercetin. Petroselinum sativum extracts also showed no evidence of hepatotoxicity nor nephrotoxicity, with remarkable anti-inflammatory activity, as well as a significant estrogenic effect compared to negative control. Conclusion: This study provides a scope of the potential use of Petroselinum sativum extracts in counteracting female infertility issues.
\end{abstract}

\section{Submission Files Included in this PDF}

File Name [File Type]

HIGHLIGHTS.docx [Highlights]

GRAPHICAL ABSTRACT.docx [Graphical Abstract]

slighoua meryem PAPER FINAL2.docx [Manuscript File]

Figure.docx [Figure]

CONFLICT OF INTERESTS.docx [Supplementary Material]

To view all the submission files, including those not included in the PDF, click on the manuscript title on your EVISE Homepage, then click 'Download zip file'.

\section{Research Data Related to this Submission}

There are no linked research data sets for this submission. The following reason is given:

Data will be made available on request 


\section{HIGHLIGHTS}

- Parsley (Petroselinum sativum) extracts are devoid of hepatotoxicity and nephrotoxicity

- Parsley elicited estrogenic activity and evident anti-inflammatory property

- Parsley extracts increased uterine weight of treated female Wistar rats

- Parsley reduced serum and ovarian cholesterol level 


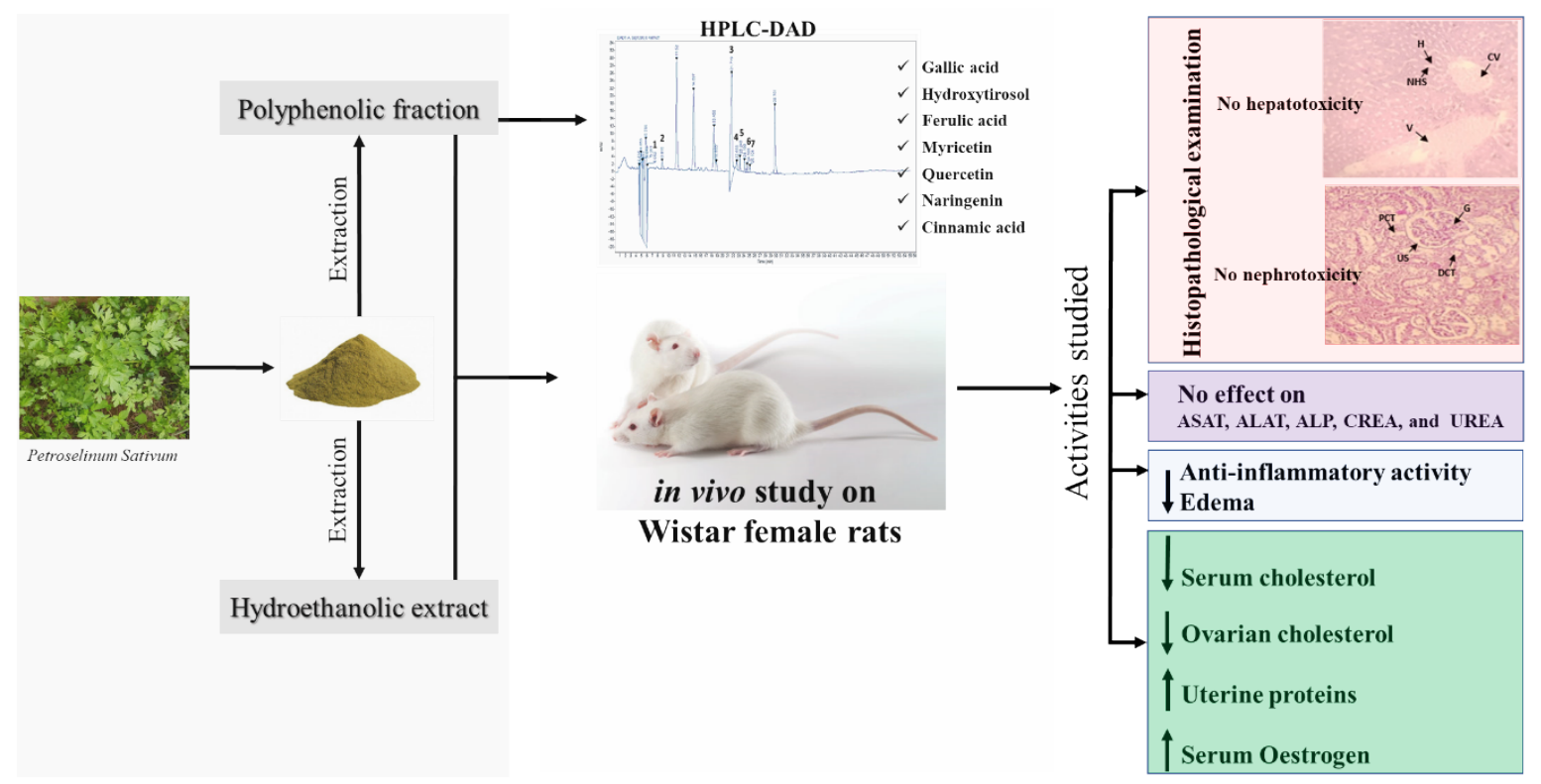




\section{Assessment of in vivo estrogenic and anti-inflammatory activities of the hydro-ethanolic extract and polyphenolic fraction of Parsley (Petroselinum sativum Hoffm.)}

Slighoua Meryem ${ }^{1 *}$, Amrati Fatima ez-zahra1, Mahdi Ismail 2,3, Di Cristo Francesca ${ }^{4}$, Amaghnouje Amal' ${ }^{1}$, Grafov Andrey ${ }^{5}$, Boucetta Nabil ${ }^{6}$, Bari Amina ${ }^{7}$, Bousta Dalila ${ }^{1}$

${ }^{1}$ Laboratory of Neuroendocrinology and Nutritionnel and Climatic Environment, University of Sidi-Mohamed-Ben-Abdellah, FSDM-Fez, Morocco.

${ }^{2}$ Medical Application Interface Center, Mohammed VI Polytechnic University, Ben-Guerir, Morocco.

${ }^{3}$ Laboratory of Microbial Biotechnologies, Agrosciences and Environment (BioMAgE), Faculty of Sciences Semlalia, Cadi Ayyad University, Marrakesh, Morocco.

${ }^{4}$ Elleva Pharma S.R.L via PietroCastellino, 111-CNR Research area Naples 1, 80131, Naples- Italy.

${ }^{5}$ Materials Chemistry Division of the Department of Chemistry at the University of Helsinki, Finland.

${ }^{6}$ Medical Laboratory Specialized in Medical Biology, Fez, Morocco.

${ }^{7}$ Biotechnology laboratory and preservation of natural resources, University of Sidi-

Mohamed-Ben-Abdellah, FSDM-Fez, Morocco.

*Corresponding author: Slighoua Meryem, Laboratory of Neuroendocrinology and

Nutritionnel and Climatic Environment, University of Sidi-Mohamed-Ben-Abdellah,

FSDM-Fez, Morocco. Email: slighoua.meryem@gmail.com , +212603096631 


\section{Graphical abstract}

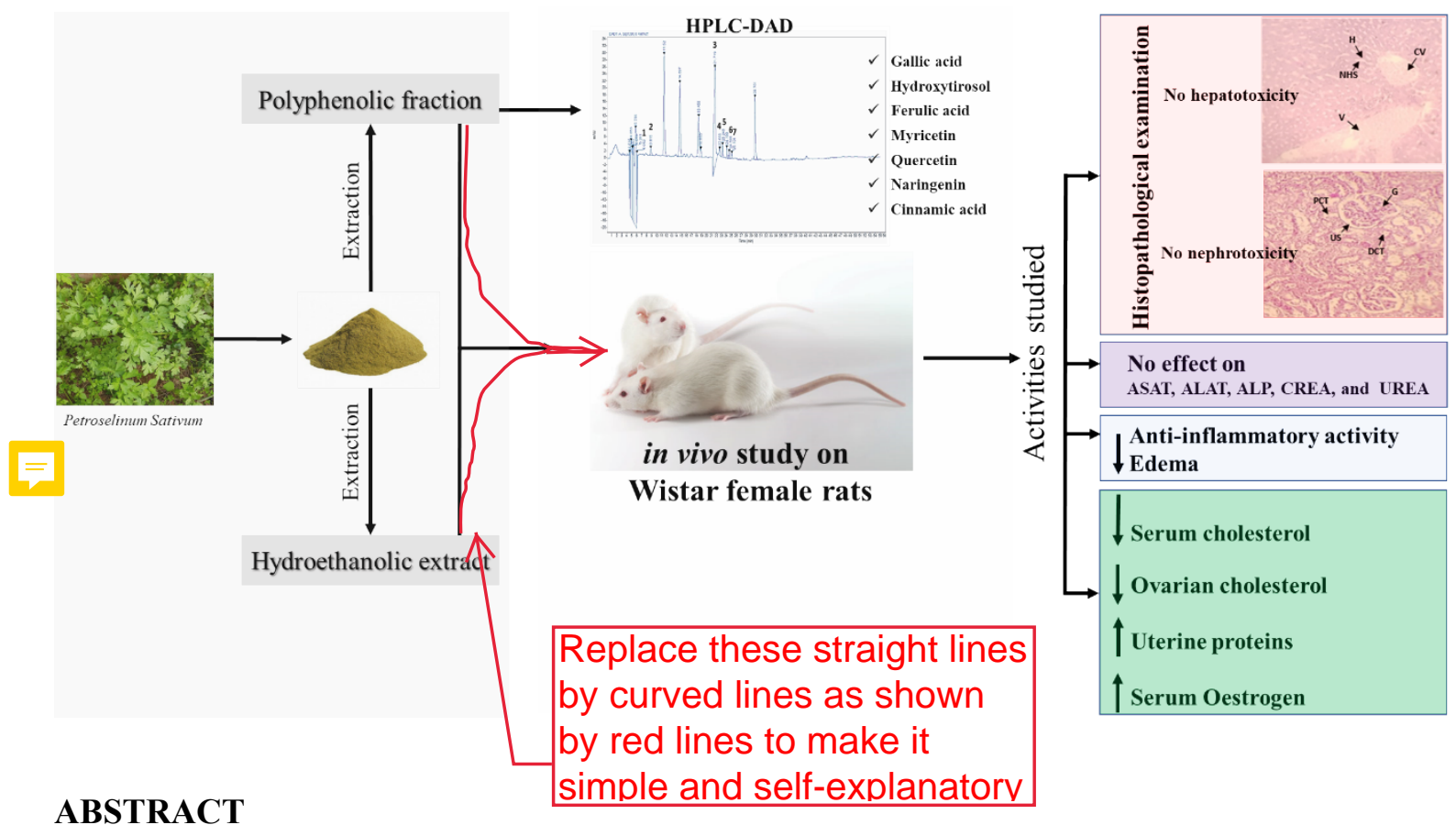

Ethnopharmacological relevance: since the dawn of time, medicinal and aromatic plants (AMPs) represent a precious heritage for humanity, especially in developing countries, who exploit their virtues in traditional pharmacopoeia to cope with health problems such as diabetes, kidney stones, ulcer, and digestive disorders. Petroselinum sativum Hoffm. belongs to family Apiaceae. It is traditionally used to treat arterial hypertension, diabetes, cardiac disease, renal disease, and recently reported as a plant endowed a female fertilizing effect.

Aim of the study: This study aims to evaluate the in vivo effect of hydro-ethanolic extract of Petroselinum sativum Hoffm. and polyphenols on cholesterol, protein and estrogen levels, and characterize the chemical composition of polyphenolic fraction. In addition, acute toxicity and anti-inflammatory activity of tested extract was also investigated. 
Materials and Methods: Chemical composition of polyphenolic fraction was determined using High-Performance Liquid Chromatography with Diode-Array Detection (HPLCDAD). First, toxicological investigations including sub-acute toxicity were performed by measuring animals' weights daily for four weeks. Afterwards, histopathological examination of livers and kidneys, and serum assay of ASAT, and ALAT were also checked. Next, the acute in vivo anti-inflammatory study of the hydro-ethanolic extract of Petroselinum sativum Hoffm. and polyphenols versus Indomethacin was conducted. Furthermore, we evaluated the estrogenic effect of its hydro-ethanolic extract and the polyphenolic fraction following biochemical assays for the determination of proteins, cholesterol and estrogen levels.

Results: The results revealed the presence of some phenolic compounds mainly Ferulic acid, gallic acid and quercetin. Petroselinum sativum Hoffm. extracts also showed no evidence of hepatotoxicity nor nephrotoxicity, with remarkable anti-inflammatory activity, as well as a significant estrogenic effect compared to negative control.

Conclusion: This study provides a scope of the potential use of Petroselinum sativum Hoffm. extracts in counteracting female infertility issues.

Key words: Petroselinum sativum Hoffm., Sub-acute toxicity, Histopathological examination, Anti-inflammatory activity, Estrogenic effect.

Abbreviations: ASAT, Aspartate aminotransferase; ALAT, Alanine transaminase; ALP, Alkaline phosphatase; CREA, Creatinine; HES, Hematoxylen-eosin-safran; PCT, Proximal convoluted tubules; DCT, Distal convoluted tubules; HS, Hepatic sinusoid; CV, Central vein; H, Hepatocytes; G, Glomerulus. 


\section{Introduction}

Aromatic and medicinal plants (AMPs) are therapeutic heritage having vital roles in health care. They have been used by all civilization throughout history and their use is still widespread worldwide, especially by African population (Rao et al., 2004). From aspirin to taxol, the modern pharmaceutical industry itself relies heavily on the diversity of plant secondary metabolites to discover new molecules with biological and pharmacological properties (Sofowora, 1996; Balandrin et al., 1985). It has been reported by several studies that for a long time, the inhabitants of all continents applied the poultice of native plants and infusion. Nowadays, $80 \%$ of the population in developing countries still use medicinal plants for the treatment of various diseases (Nations, 1997), like female infertility (Ogbuewu et al., 2011), one of the fundamental characteristics of living organisms and their ability to reproduce and thus ensure continuity of live.

There are different types of infertility that are female infertility (35\%), male (20\%), shaking of both (20\%), and idiopathic or unexplained infertility (15\%) (Evers, 2002; Guzick et al., 1997). Endometriosis, ovulatory dysfunction and tubal injury represent the main causes of female infertility.

Several studies have evaluated the effect of plants on female infertility. For instance, the aqueous extract of coccinia cordifolia which showed a fertilizing effect (Jha et al., 2010), the aqueous extract of senecio biafrea which improved the physiological and biochemical parameters of fertility (Lienou et al., 2015), and the leaves of holarrhena floribunda which was suggested as phytoestrogen that compresses itself as an agonist (Bayala et al., 2006). 
An ethnopharmacological survey was conducted in 2017 in Morocco among women and herbalists to identify medicinal plants used in the treatment of female infertility. The results showed that Petroselinum sativum Hoffm. was among the most cited plants (Slighoua et al., 2019). Indeed, other studies in other countries revealed the traditional use of parsley in the treatment of female infertility (Fata et al., 2019; Fongod et al., 2013; Nazik et al., 2015).

Petroselinum sativum Hoffm. commonly called "Parsley" in English and "Maadnous" in Arabic, belongs to the family of Apiaceae. The synonyms of Petroselinum sativum Hoffm. are Petroselinum.crispum (Mill) Fuss, Apium petroselinum L., Apium crispum Mill, and Petroselinum hortense Hoffm.(Agyare et al., 2017). Parsley is originally from Mediterranean region, but currently cultivated all over the world (Mahmood et al., 2014). Petroselinum sativum Hoffm. have several beneficial activities mainly antioxidant, analgesic and spasmolytic, antidiabetic, immunomodulating, and gastrointestinal effects (Farzaei et al., 2013). These different virtues could be due to the main constituents of this plant such as flavonoids (Apigenin, Apiin, Quercetin, Luteolin, Kaempferol), carotenoids, vitamin and coumarin. (Chaves et al., 2011; Kreuzaler and Hahlbrock, 1973).

This study aims to evaluate the in vivo effect of hydro-ethanolic extract of Petroselinum sativum Hoffm. and polyphenols on cholesterol, protein and estrogen levels, and characterize the chemical composition of polyphenolic fraction. In addition, acute toxicity and anti-inflammatory activity of tested extract was also investigated.

\section{Materials and Methods}

\subsection{Harvesting method and botanical identification of studied plant}


The aerial part of Petroselinum sativum Hoffm. plant (Fig. 1) was harvested in spring 2018. before sunrise in the Taounate region. This region is situated in the North of Moroccan country in the Rif Mountains, north-east of Fez. Determination of the botanical name of the plant was done by Pr Bari Amina and the sample is available at the herbarium of the Faculty of Sciences Dhar El Mahrez in Fez under a voucher number of 18TA5001. This was confirmed on the Word Flora Online database ${ }^{1}$. Our plant corresponds indeed to Petroselinum sativum Hoffm., whose synonym is Petroselinum crispum (Mill) Fuss.

\subsection{Preparation of hydro-ethanolic extract}

The preparation of plant extracts was made according to the method of Wafa et al., (2014) with some modifications. To prepare the hydro-ethanolic extract, $100 \mathrm{~g}$ of the grind was macerated with 1L of EtOH 99\% - distilled water (70-30, v/v) for 48 hours at room temperature. The Macerate was then filtered through Whathman paper and evaporated to dryness using a rotary evaporator at $37^{\circ} \mathrm{C}$. A yield of $23.85 \%$ was obtained.

\subsection{Preparation of polyphenolic fraction}

One hundred grams of Petroselinum sativum Hoffm. powder was extracted three times with $300 \mathrm{ml}$ of methanol at $50^{\circ} \mathrm{C}$ for $3 \mathrm{hr}$. at the end of the incubation, Solvent was evaporated from the combined extract using a rotary evaporator. Afterwards, the extract was dissolved in $500 \mathrm{ml}$ of water and extracted three times in $200 \mathrm{ml}$ hexane and then in $200 \mathrm{ml}$ chloroform to remove chlorophyll and caffeine residues. Next, the aqueous phase was in turn extracted three times in $200 \mathrm{ml}$ ethyl acetate, and the ethyl acetate was evaporated under

\footnotetext{
${ }^{1}$ http://www.worldfloraonline.org/taxon/wfo-0000745326
} 
reduced pressure. The residue was redissolved in $300 \mathrm{ml}$ water and freeze-dried to obtain the polyphenol extract (Ho, 1992). The yield of the polyphenolic extract was $10.52 \%$.

\subsection{HPLC-DAD analysis}

Quercetin, gallic acid, ferulic acid, hydroxytyrosol, naringenin, myristine, and cinnamic acid (Sigma-aldrich, steinheim,Germany) were used as standards for HPLC analysis. Stock solutions of all standards were prepared in methanol and working concentration of each one was made by diluting stock solution in methanol to yield $62.5 \%$. Standard solutions were stored at $-18^{\circ} \mathrm{C}$.

Polyphenolic extract of petroselinum sativum Hoffm. was analyzed using HPLC coupled with a UV detector and equipped with a quaternaru pump. The monitoring wavelength was $280 \mathrm{~nm}$. The separation was achieved on a $5 \mu \mathrm{m}, 4.6 \times 150 \mathrm{~mm}$ column with a $\mathrm{C} 18$ (zorbax eclipse plus) column. Temperature of the column oven was set at $35^{\circ} \mathrm{C}$. The mobile phase was composed of acidified water $0.1 \%$ (A) and Acetonitrile (B). The gradient adopted was similar to that adopted for determination of phenolics in wine (García Parrilla et al., 1999) with some modification: $50 \% \mathrm{~A}, 50 \% \mathrm{~B}, 0-40 \mathrm{~min} ; 40 \% \mathrm{~A}, 60 \% \mathrm{~B}, 40-45 \mathrm{~min}$; $100 \% \mathrm{~B}, 40-60 \mathrm{~min} ; 96 \% \mathrm{~A}$, and $4 \% \mathrm{~B}, 60-65 \mathrm{~min}$. The flow rate was $1 \mathrm{ml} / \mathrm{min}$, and the injection volume was $10 \mu 1$.

Based on retention time (RT) and spectral matching, each compound was identified, and the concentration was calculated according to the following equation:

$$
\text { Concentration }(\mu \mathrm{g} / \mathrm{ml})=\frac{\text { Area sample }}{\text { area standard }} \times 100
$$




\subsection{Animal handling and housing}

Wistar rats obtained from the animal house of the Department of Biology, Faculty of Science, Fez, were used in this study. The average weight of the female rats was $193 \pm 13 \mathrm{~g}$. At the animal house, the temperature is $28-31^{\circ} \mathrm{C}$, relative humidity is between $50-55 \%$. The rats were subjected every day to a photoperiod $\mathrm{D} / \mathrm{N}$ cycle $(\sim 12 / 12 \mathrm{~h})$ and have free access to food and water. The handling and care of the animals were carried out following the guidelines of the internationally accepted standard as described in directive EEC/86/EEC of the European community (Union, 1986).

\subsection{Administration of extracts}

Different doses of the plant were prepared in distilled water and administered orally according to the body weight of the animals. Physiological water ( $\mathrm{NaCl} 0.9 \%$ ) was administered to the negative control group.

As For the toxicity test, the rats (female and male) were divided randomly into 4 groups of 5 each. The first group received physiological water; the second clomiphene citrate $308.33 \mathrm{mg} / \mathrm{kg}$ (positive control), the third and fourth groups received 500 and $1000 \mathrm{mg} / \mathrm{kg}$ of hydro-ethanolic extract of parsley, respectively for 4 weeks.

For the anti-inflammatory test, the rats (female and male) were divided randomly into 5 groups of 5 each. The first group received physiological water; the second indomethacin $10 \mathrm{mg} / \mathrm{kg}$ (positive control), the third and fourth groups received 500 and $1000 \mathrm{mg} / \mathrm{kg}$ of hydro-ethanolic extract of parsley, and the fifth group received polyphenols $100 \mathrm{mg} / \mathrm{kg}$. The total time of the test is 6 hours. 
For the female infertility test, twenty-five female rats were divided randomly into 5 groups of 5 each. The first group received physiological water; the second clomiphene citrate $308.33 \mathrm{mg} / \mathrm{kg}$ (Positive control), the third and fourth groups received 500 and $1000 \mathrm{mg} / \mathrm{kg}$ of hydro-ethanolic extract of parsley, and the fifth group received polyphenols $100 \mathrm{mg} / \mathrm{kg}$, respectively for 4 weeks.

\subsection{Sub-acute Toxicity parameters}

Sub-acute toxicity was determined from OECD Guideline 407 (Andrews et al., 2001). Before and after the administration of the extract, the signs of toxicity were monitored daily in all animals during the 4 weeks of study, and the weighing was also carried out every day. On the $29^{\text {th }}$ day, the blood of anesthetized animals was drawn from tubes containing heparin to perform the assay of some serum biochemical parameters namely ASAT, ALAT, ALP, CREA, UREA.

\subsection{Histopathological examination}

Livers and kidneys were isolated, kept in $10 \%$ formalin solution until histopathological examination by following standard anatomic pathology techniques, namely fixation, dehydration, paraffin embedding, microtome sections, Hematoxylen-Eosin-Safran (HES) staining and observation using an optical microscope.

\subsection{Anti-inflammatory activity}

The anti-inflammatory activity was carried out according to the method described by winter and al. (Winter et al., 1962). Firstly, rats were randomly assigned to 5 groups of 5 rats each. Group 1 and 2 correspond respectively to the negative and positive control that received 
physiological water $(\mathrm{NaCl} 0.9 \%)$ and indomethacin $(10 \mathrm{mg} / \mathrm{kg})$. The third and fourth groups received oral doses of 500 and $1000 \mathrm{mg} / \mathrm{kg}$ of Body weight of the hydro-ethanolic extract of Petroselinum sativum Hoffm., respectively. While polyphenols at the dose $100 \mathrm{mg} / \mathrm{kg}$ were administered to the fifth group. The volume of the paw was measured before the injection of $1 \%$ carrageenin into the right paw of rats and measured again periodically after $3 \mathrm{~h}, 4 \mathrm{~h}, 5 \mathrm{~h}$ and $6 \mathrm{~h}$ of the injection. The inhibitory activity was calculated according to the following equation:

$$
\text { Percent inhibition }=100\left[1-\left(\frac{a-x}{b-y}\right)\right]
$$

Where: ' $a$ ' is the mean paw volume after carrageenan injection. ' $x$ ' is the mean paw volume of treated rats before injection. ' $b$ ' is the mean paw volume of control rats after carrageenan injection and ' $y$ ' is the mean paw volume of control rats before the injection.

\subsection{Dosage of serums cholesterol and estradiol}

The animals were anesthetized with Pentobarbital, then sacrificed and dissected. Cardiac blood samples were collected in EDTA tubes to prevent coagulation. To obtain the plasma, the samples were centrifuged at $3000 \mathrm{r} / \mathrm{min}$ for $10 \mathrm{~min}$. Estradiol determination was performed following the ELFA technique on biomass.

\subsection{Dosage of ovarian cholesterol and uterine proteins}

Weights of ovaries and uterus were firstly monitored and then ground with $0.9 \% \mathrm{NaCl}$ solution and then centrifuged at $4000 \mathrm{rpm}$ for $10 \mathrm{~min}$. The obtained supernatant was used as matrix of proteins determination using biuret method and cholesterol assay by the enzymatic colorimetry using the POD technique. 


\subsection{Statistical analysis}

Results were subjected to analysis of variance (ANOVA) and significance level of $\mathrm{P}$ $<0.05$ was tested by Dunnett to identify significant differences between treatments and controls. Results were expressed as mean \pm s.e.m.

\section{Results}

\subsection{HPLC analysis}

HPLC-DAD analysis of the polyphenolic extract of Petroselinum sativum Hoffm. revealed the presence of seven phenolic compounds in the form of symmetrical peaks separated from each other (Fig.2). The rate of polyphenols contained in Petroselinum sativum Hoffm. extract ranged from 0.02 to $6.3 \mu \mathrm{g} / \mathrm{ml}$. The ferulic concentration was comparatively high, up to at $6.3 \mu \mathrm{g} / \mathrm{ml}$, followed by gallic acid with $1,21 \mu \mathrm{g} / \mathrm{ml}$. The lowest concentration was detected for cinnamic acid $0.02 \mu \mathrm{g} / \mathrm{ml}$ (Table1)

\subsection{Effect of treatment on the weight evolution and toxicity parameters}

During the 28 days of treatment, no signs of toxicity, disorders in the autonomic nervous system, skin and integuments, digestive, musculoskeletal, psychiatric, or general disorders such as tiredness, fever or flushing, were noticed. All animals gained weight throughout the duration of the experiment for both control and treated groups (Fig. 3). As for the effects of the different treatments on ovarian and uterine weights, our results showed no significant difference in ovarian weights between all tested extracts (Fig. 4 (a)). However, the uterine weights showed a significant increase for the doses of hydro-ethanolic extract and polyphenols of about 30\% (P<0.01) (Fig. 4 (b)). 
In addition, no abnormal structures of histological sections of livers and kidneys were seen. Regarding liver toxicity, no histopathological changes or anomaly were observed in the structures of the Central Vein (CV), Hepatocytes (H), and Hepatic Sinusoids (HS) (Fig. 5). Similarly, observation of histological sections of kidneys demonstrated that none of the administered doses affected kidneys structures such as Glomerulus (G), Distal Convoluted Tubules (DCT), and Proximal Convoluted Tubules (PCT) (Fig. 6).

To assess liver function, we analyzed the hepatic enzymes ALAT, ASAT and ALP. The results of ASAT and ALP did not show toxicity, while the ALAT showed a slight toxicity $(\mathrm{p}<0.01,45 \%)$ at the level of clomiphene citrate molecule (Table 2). In addition, the various concentrations of Petroselinum sativum Hoffm. extract did not negatively influence the kidney function parameters (UREA, CREA) (Table 2).

\subsection{Effect of the extracts on anti-inflammatory activity}

The effect of the hydro-ethanolic and polyphenolic extracts of Petroselinum sativum Hoffm. and indomethacin on the evolution of rat paw volume $(\mathrm{n}=5)$ is closely dependent on the carrageenin-induced edema perimeter as well as on function time. As results, after 3 hours of injection of $1 \%$ carrageenin into the left paw of rats treated with $\mathrm{NaCl}$, its circumference increased gradually to reach a maximum of $2.72 \mathrm{~cm} \pm 0.03$. The groups treated with the extracts of Petroselinum sativum Hoffm. showed significant inhibition of edema $(\mathrm{p}<0.05)$, by $48 \%$ for the polyphenols, $38 \%$ for the dose $1000 \mathrm{mg} / \mathrm{kg}$ of hydro-ethanolic

extract and $25 \%$ for the dose $500 \mathrm{mg} / \mathrm{kg}$. The inhibition increases at the sixth hour, it was of $81.33 \%$ for the polyphenols, $74 \%$ for the dose $1000 \mathrm{mg} / \mathrm{kg}$ and $65.33 \%$ for the dose 500 
$\mathrm{mg} / \mathrm{kg}$, while the reference group of indomethacin reduced edema by $50 \%$ inhibition at $3 \mathrm{~h}$ and $86.67 \%$ at $6 \mathrm{~h}$. The results are shown in table (3).

\subsection{Effect of different extracts on serum and ovarian cholesterol, uterine proteins and serum estradiol}

The biochemical changes in serum and ovarian cholesterol after 4 weeks of oral administration of the Petroselinum sativum Hoffm. hydro-ethanolic and polyphenolic extract to mature rats are shown in fig. 7 . The serum cholesterol level decreased significantly ( $\mathrm{p}$ $<0.05,36 \%$ ) using $1000 \mathrm{mg} / \mathrm{kg}$ per $\mathrm{kg}$ of Petroselinum sativum Hoffm. and very significantly by polyphenol and clomiphene citrate $(\mathrm{p}<0.001,26 \%)$ compared to the control. These decreases were slightly correlated with decreases in ovarian cholesterol, which decreased significantly for the dose $1000 \mathrm{mg} / \mathrm{kg}(\mathrm{p}<0.001,56 \%)$ and clomiphene citrate $(\mathrm{p}<0.001,50 \%)$, and a very significant decrease was observed for the polyphenols $(\mathrm{p}<0.01$, $40 \%$ ) as compared to the negative control.

Oral administration of the hydro-ethanolic extract of Petroselinum sativum Hoffm. for 4 weeks showed a significant increase in uterine protein levels at the dose of $1000 \mathrm{mg} / \mathrm{kg}$ $(\mathrm{p}<0.01,73 \%)$ and polyphenols $(\mathrm{p}<0.05,65 \%)$ compared to negative control. The results are shown in fig. 8 .

Comparatively to the negative control, oral administration of hydro-ethanolic extract of Petroselinum sativum Hoffm. induced an extremely significant increase in serum estradiol $(\mathrm{p}<0.001)$ by $1000 \mathrm{mg} / \mathrm{kg}(43 \%)$ and the dose $100 \mathrm{mg} / \mathrm{kg}$ of Polyphenols $(31 \%)$. In the 
positive control group (clomiphene citrate), a significant increase in serum estradiol was noticed ( $<<0.001,64 \%)$ (Fig. 9).

\section{Discussion}

In this study, we assessed the estrogenic effect of the hydro-ethanolic extract and the polyphenolic fraction of parsley. Our findings showed neither death nor signs of toxicity on liver or kidney parameters after 4 weeks of treatment of female rats. Regarding the biochemical parameters namely ASAT, ALAT, ALP, UREA and CREA), groups treated at doses of 500 and $1000 \mathrm{mg} / \mathrm{kg}$ did not show any significant modification compared to the negative control after an oral administration for 4 weeks.

ALAT and ASAT are cytoplasmic hepatic enzymes, their increase in plasma induces liver damage caused by drugs (Awe and Banjoko, 2013). The activities of these enzymes in body fluids and tissues play a major role in the diagnosis, disease investigation and liver toxicity (Larrey, 2002). Thereby, our results highlighted the biosafety of tested extracts on the hepatic function. In contrast, the study of (Awe and Banjoko, 2013) realized in Nigeria, showed some hepatotoxic and nephrotoxic effects of parsley following administration at dose of $1000 \mathrm{mg} / \mathrm{kg}$ and no toxicity at lower doses. This was explained by the duration of treatment which was 8 weeks. However Jassim, (2013) (Jassim, 2013), showed the protective effect of parsley on kidney damage induced by valproic acid and anti-hepatotoxic activities at the dose $200 \mathrm{mg} / \mathrm{kg}$. It has been also demonstrated that Parsley serves as a diuretic and is beneficial to the kidneys (Kreydiyyeh and Usta, 2002). Similarly, we demonstrated here that our Parsley's extracts did not affect kidney function parameters (UREA, CREA). 
Female infertility may be due to damage or alteration of fallopian tubes or obstruction caused by infection or inflammation (Wiesenfeld et al., 2012). Our results revealed that parsley polyphenols at the dose of $100 \mathrm{mg} / \mathrm{kg}$, have the most significant protective effects on inflammation induced by the carrageenan test after 4 hours followed by the hydro-ethanolic extract of Petroselinum sativum Hoffm. at the dose of and $500 \mathrm{mg} / \mathrm{kg}$ and1000 mg/kg. The carrageenan-induced inflammation test is an assay used to evaluate anti-inflammatory drugs and natural products against inflammation (Ferrándiz and Alcaraz, 1991; Della Loggia et al., 1986; Winter et al., 1962). Previous studies realized on the ethanolic extract of parsley have also shown its anti-inflammatory effect (Farzaei et al., 2013; Alhowiriny et al., 2003). Several mechanisms of cellular action explain the anti-inflammatory activity of polyphenols and flavonoids $\overline{\mathbf{z}}_{\overline{2}}$ essentially flavone derivatives, which modulate the expression of proinflammatory molecules by inhibiting the activation of some transcription factors (Kim et al., 2004).

After 4 weeks of treatment of mature female rats with hydro-ethanolic and polyphenolic extract of Petroselinum sativum Hoffm., the results showed a significant increase in the uterine weight of treated animals, which could be related to the presence of estrogenic compounds. In fact, estrogens and their precursors induce cell proliferation by activating the synthesis of biomolecules in target organs, which consequently leads to an increase in the weight of uterus and ovaries (Lienou et al., 2015; Jensen and DeSombre, 1972). In addition, a significant decrease was noticed in serum and ovarian cholesterol levels for the dose of $1000 \mathrm{mg} / \mathrm{kg}$ of hydro-ethanolic extract and $100 \mathrm{mg} / \mathrm{kg}$ of polyphenols.

This could be explained by the fact that cholesterol is the precursor for steroid hormones (Black et al., 1994; Strauss et al., 1981). Similarly, previous works have shown 
similar results regarding the decrease in cholesterol level following treatment with phytoestrogen (Telefo et al., 2011; Bayala et al., 2006). Moreover, we identified, following HPLC-DAD analysis, some phenolic compounds in Petroselinum sativum Hoffm. mainly ferulic acid, gallic acid and quercetin. Comparatively, previous studies have shown that Parsley contain Myricetin (Yıldız et al., 2008), Gallic acid (Condrata et al., 2011), ferulic acid and quercetin (Plazonić et al., 2009). Our results corroborate that parsley plant is rich in phenolic compounds.

Proteins are the major constituents of cells. It is well established that the anabolic and mitogenic effect of estrogen induces cell proliferation (Bayala et al., 2006). Here, uterine protein determination revealed that our extracts exhibit a positive effect on uterine proteins synthesis. Similarly, other researchers have demonstrated the positive effects of estrogenic substances in increasing proteins level (Bend et al., 2018; Lee and Lee, 1996).

Our findings showed a significant increase in serum estradiol following administration of extracts at the dose $1000 \mathrm{mg} / \mathrm{kg}$ and polyphenols at $100 \mathrm{mg} / \mathrm{kg}$ compared to the negative control, indicating the potential presence of secondary metabolites such as genistein, daidzein, and lignans which act on the mammalian reproduction pathways (Lienou et al., 2015; Wilkinson et al., 2002). Similarly, several reported data have demonstrated the effect of polyphenols and flavonoids as active substances having estrogenic effects (Bayala et al., 2006; Limer and Speirs, 2004).

\section{Conclusion}


The present investigation aimed to evaluate the in vivo estrogenic and antiinflammatory effect of the hydro-ethanolic extract and polyphenols of Parsley. We found that the hydro-ethanolic extract and the polyphenols fraction of Parsley have no toxicity after oral administration for 4 weeks. The results showed a decrease in cholesterol levels in the serum and ovaries and significant increase in protein level in the uterus and estradiol in the serum. In addition, the hydro-ethanolic extract and polyphenols of Parsley plant have shown antiinflammatory effect. Our findings provide evidence of estrogenic effects of this plant's extracts. Although this provides evidence of the efficacy of parsley extracts in inflammation and infertility, further, investigations would also be needed to determine the precise mechanisms by which these extracts affect the studied parameters and to perform the same tests on other parsley fractions such as flavonoids and its derivatives. Ultimately, this study opens up the possibility to assess the potential of Parsley in counteracting female infertility.

\section{Author contributions}

Conceptualization, B.D. and S.M.; methodology, B.D., B.N, S.M., A.F, D.F., A.A.; software, S.M.; validation, B.D., S.M; formal analysis, D.B, S.M.; investigation, B.D., B.N, S.M., A.F, D.F., G.A.,S.M.; data curation, B.D, S.M.; writing-original draft preparation, S.M.; writing — review and editing, D.B., B.A., M.I., S.M, supervision, B.D.; All authors have read and agreed to the published version of the manuscript.

\section{Acknowledgments}

We would like to extend our sincere thanks to the project H2020-MSCA-RISE-Marie SklodowskaCurie Actions (MSCA) Research and innovation Staff Exchange (RISE), Project Acronym: VAHVISTUS-Project Number: 734759. 


\section{Conflict of interests}

The authors have not declared any conflict of interests.

\section{References}

Agyare, C., Appiah, T., Boakye, Y.D., Apenteng, J.A., 2017. Chapter 25 - Petroselinum crispum: a Review, in: Kuete, V. (Ed.), Medicinal Spices and Vegetables from Africa. Academic Press, pp. 527-547. https://doi.org/10.1016/B978-0-12-809286-6.00025-X

Alhowiriny, T., Al-Sohaibani, M.O., El-Tahir, K.H., Rafatullah, S., 2003. Preliminary evaluation of the anti-inflammatory and anti-hepatotoxic activities of "Parsley" Petroselinum crispum in rats. J. Nat. Remedies 3, 54-62.

Andrews, P., Freyberger, A., Hartmann, E., Eiben, R., Loof, I., Schmidt, U., Temerowski, M., Becka, M., 2001. Feasibility and potential gains of enhancing the subacute rat study protocol (OECD test guideline no. 407) by additional parameters selected to determine endocrine modulation. A pre-validation study to determine endocrine-mediated effects of the antiandrogenic drug flutamide. Arch. Toxicol. 75, 65-73. https://doi.org/10.1007/s002040100214

Awe, E., Banjoko, S., 2013. Biochemical and haematological assessment of toxic effects of the leaf ethanol extract of Petroselinum crispum (Mill) Nyman ex A.W. Hill (Parsley) in rats. https://doi.org/10.1186/1472-6882-13-75

Balandrin, M.F., Klocke, J.A., Wurtele, E.S., Bollinger, W.H., 1985. Natural plant chemicals: source of industrial and medicinal materials. Sci. Wash. DC U. S. 228. https://doi.org/10.1126/science.3890182

Bayala, B., Tamboura, H.H., Pellicer, M.R., Zongo, D., Traoré, A., Ouédraogo, L., Malpaux, B., 2006. Effets ø estrogéniques du macéré aqueux des feuilles de Holarrhena floribunda (G. Don) Dur \& Schinz chez la rate ovariectomisée. Biotechnol. Agron. Société Environ. $10,173-180$. 
Bend, E.F., Oundoum, P.C.O., Njila, M.I.N., Koloko, B.L., Nyonseu, C.D., Mandengue, S.H., Moundipa, P., Dimo, T., Lembè, D.M., 2018. Effect of the Aqueous Extract of Schumanniophyton magnificum Harms on Sexual Maturation and Fertility of Immature (K. schum) Female Rat. Pharmacol. Amp Pharm. 9, 415-427. https://doi.org/10.4236/pp.2018.910031

Black, L.J., Sato, M., Rowley, E.R., Magee, D.E., Bekele, A., Williams, D.C., Cullinan, G.J., Bendele, R., Kauffman, R.F., Bensch, W.R., 1994. Raloxifene (LY139481 HCI) prevents bone loss and reduces serum cholesterol without causing uterine hypertrophy in ovariectomized rats. J. Clin. Invest. 93, 63-69. https://doi.org/10.1172/JCI116985

Chaves, D.S.A., Frattani, F.S., Assafim, M., de Almeida, A.P., de Zingali, R.B., Costa, S.S., 2011. Phenolic chemical composition of Petroselinum crispum extract and its effect on haemostasis. Nat. Prod. Commun. 6, 961-964.

Condrata, D., Crişanb, F., Harjaa, F., 2011. Quantitative analysis of gallic acid from apium graveolens, equisetum arvense 1. and petroselinum crispum using high performance liquid chromatography - ProQuest. Annals of west university of timisoara, Chemistry 5.

Della Loggia, R., Tubaro, A., Dri, P., Del Negro, P., 1986. The role of flavonoids in the antiinflammatory activity of Chamomilla recutita. 213, 481-484.

Evers, J.L., 2002. Female subfertility. The Lancet 360, 151-159. https://doi.org/10.1016/S0140-6736(02)09417-5

Farzaei, M.H., Abbasabadi, Z., Ardekani, M.R.S., Rahimi, R., Farzaei, F., 2013. Parsley: a review of ethnopharmacology, phytochemistry and biological activities. J. Tradit. Chin. Med. 33, 815-826. https://doi.org/10.1016/S0254-6272(14)60018-2

Fata, S., Tokat, M.A., Bagardi, N., Yilmaz, B., 2019. The traditional practices used by couples with fertility problems, affecting factors, expected benefits, and learning paths: The Turkey Sample. Niger. J. Clin. Pract. 22, 806. https://doi.org/10.4103/njcp.njcp_383_18

Ferrándiz, M.L., Alcaraz, M.J., 1991. Anti-inflammatory activity and inhibition of arachidonic acid metabolism by flavonoids. Agents Actions 32, 283-288.

Fongod, A.G.N., Veranso, M.C., Libalah, M.N., 2013. IDENTIFICATION AND USE OF PLANTS IN TREATING INFERTILITY IN HUMAN FEMALES IN FAKO 
DIVISION, CAMEROON - ProQuest. Global J Res. Med. Plants \& Indigen. Med. 2, 724-737.

Garcia Parrilla, M.C., Heredia, F.J., Troncoso, A.M., 1999. Sherry wine vinegars: phenolic composition changes during aging. Food Res. Int. 32, 433-440. https://doi.org/10.1016/S0963-9969(99)00105-2

Guzick, D.S., Silliman, N.P., Adamson, G.D., Buttram, V.C., Canis, M., Malinak, L.R., Schenken, R.S., 1997. Prediction of pregnancy in infertile women based on the American Society for Reproductive Medicine's revised classification of endometriosis. Fertil. Steril. 67, 822-829. https://doi.org/10.1016/S0015-0282(97)81392-1

Ho, C.T., 1992. Antioxidative effect of polyphenol extract prepared from various Chinese teas. Prev Med 21, 520-525.

Jassim, A.M., 2013. Protective Effect of Petroselinum crispum(parsley)extract on histopathological changes in liver ,kidney and pancreas induced by Sodium Valproate- In male Rats. Kufa J. Vet. Med. Sci. 4, 20-27.

Jensen, E.V., DeSombre, E.R., 1972. Mechanism of Action of the Female Sex Hormones. Annu. Rev. Biochem. 41, 203-230. https://doi.org/10.1146/annurev.bi.41.070172.001223

Jha, U., Asad, M., Asdaq, S.M.B., Das, A.K., Prasad, V.S., 2010. Fertility inducing effect of aerial parts of Coccinia cordifolia L. in female rats. J. Ethnopharmacol. 127, 561-564. https://doi.org/10.1016/j.jep.2009.10.021

Kim, H.P., Son, K.H., Chang, H.W., Kang, S.S., 2004. Anti-inflammatory plant flavonoids and cellular action mechanisms. J. Pharmacol. Sci. 96, 229-245.

Kreuzaler, F., Hahlbrock, K., 1973. Flavonoid glycosides from illuminated cell suspension cultures of Petroselinum hortense. Phytochemistry 12, 1149-1152. https://doi.org/10.1016/0031-9422(73)85031-9

Kreydiyyeh, S.I., Usta, J., 2002. Diuretic effect and mechanism of action of parsley. J. Ethnopharmacol. 79, 353-357. https://doi.org/10.1016/s0378-8741(01)00408-1

Larrey, D., 2002. Epidemiology and Individual Susceptibility to Adverse Drug Reactions Affecting the Liver. Semin. Liver Dis. 22, 145-156. https://doi.org/10.1055/s-2002-30105 
Lee, P.-C., Lee, W., 1996. In Vivo Estrogenic Action of Nonylphenol in Immature Female Rats. Bull. Environ. Contam. Toxicol. 57, 341-348. https://doi.org/10.1007/s001289900196

Lienou, L.L., Telefo, P.B., Njimou, J.R., Nangue, C., Bayala, B.R., Goka, S.C., Biapa, P., Yemele, M.D., Donfack, N.J., Mbemya, J.T., Tagne, S.R., Rodrigues, A.P.R., 2015. Effect of the aqueous extract of Senecio biafrae (Oliv. \& Hiern) J. Moore on some fertility parameters in immature female rat. J. Ethnopharmacol. 161, 156-162. https://doi.org/10.1016/j.jep.2014.12.014

Limer, J.L., Speirs, V., 2004. Phyto-oestrogens and breast cancer chemoprevention. Breast Cancer Res. 6, 119. https://doi.org/10.1186/bcr781

Mahmood, S., Hussain, S., Malik, F., 2014. Critique of medicinal conspicuousness of Parsley(Petroselinum crispum): a culinary herb of Mediterranean region. Pak. J. Pharm. Sci. 27, 193-202.

Nations, F. and A.O. of the U., 1997. Medicinal Plants for Forest Conservation and Health Care. Food \& Agriculture Org.

Nazik, E., Apay, S., Özdemir, F., Nazik, H., 2015. Traditional Practices of Turkish infertile women: an example from a rural county. Coll. Antropol. 39, 21-25.

Ogbuewu, I.P., Unamba-Oparah, I.C., Odoemenam, V.U., Etuk, I.F., Okoli, I.C., 2011. The potentiality of medicinal plants as the source of new contraceptive principles in males. North Am. J. Med. Sci. 3, 255-263. https://doi.org/10.4297/najms.2011.3250

Plazonić, A., Bucar, F., Maleš, Ž., Mornar, A., Nigović, B., Kujundžić, N., 2009. Identification and Quantification of Flavonoids and Phenolic Acids in Burr Parsley (Caucalis platycarpos L.), Using High-Performance Liquid Chromatography with Diode Array Detection and Electrospray Ionization Mass Spectrometry. Molecules 14, 24662490. https://doi.org/10.3390/molecules14072466

Rao, M.R., Palada, M.C., Becker, B.N., 2004. Medicinal and aromatic plants in agroforestry systems, in: Nair, P.K.R., Rao, M.R., Buck, L.E. (Eds.), New Vistas in Agroforestry: A Compendium for 1st World Congress of Agroforestry, 2004, Advances in Agroforestry. Springer Netherlands, Dordrecht, pp. 107-122. https://doi.org/10.1007/978-94-017-2424$1 \_8$ 
Slighoua, M., Mahdi, I., Amrati, F.E., Boukhira, S., Youbi, A.E.H.E., Bari, A., Bousta, D., 2019. Ethnopharmacological Survey of Medicinal Plants Used in the Traditional Treatment of Female Infertility in Fez Region, Morocco. Phytothérapie. https://doi.org/10.3166/phyto-2019-0194

Sofowora, A., 1996. Medicinal plants and traditional medicine in Africa. Med. Plants Tradit. Med. Afr.

Strauss, J.F., Schuler, L.A., Rosenblum, M.F., Tanaka, T., 1981. Cholesterol Metabolism by Ovarian Tissue, in: Paoletti, R., Kritchevsky, D. (Eds.), Advances in Lipid Research. Elsevier, pp. 99-157. https://doi.org/10.1016/B978-0-12-024918-3.50009-5

Telefo, B.P., Tagne, S.R., Koona, O.E.S., Yemele, D.M., Tchouanguep, F.M., 2011. Effect of the aqueous extract of justicia insularis t. Anders (acanthaceae) on ovarian folliculogenesis and fertility of female rats. Afr. J. Tradit. Complement. Altern. Med. AJTCAM 9, 197-203.

Union, P.O. of the E., 1986. Council Directive 86/609/EEC of 24 November 1986 on the approximation of laws, regulations and administrative provisions of the Member States regarding the protection of animals used for experimental and other scientific purposes, CELEX1 [WWW Document]. URL https://op.europa.eu:443/en/publication-detail//publication/cc3a8ccb-5a30-4b6e-8da8-b13348caeb0c/language-en (accessed 12.21.19).

Wafa, G., Amadou, D., Larbi, K.M., Héla, E.F.O., 2014. Larvicidal activity, phytochemical composition, and antioxidant properties of different parts of five populations of Ricinus communis L. Ind. Crops Prod. 56, 43-51. https://doi.org/10.1016/j.indcrop.2014.02.036

Wiesenfeld, H.C., Hillier, S.L., Meyn, L.A., Amortegui, A.J., Sweet, R.L., 2012. Subclinical pelvic inflammatory disease and infertility. Obstet. Gynecol. 120, 37-43. https://doi.org/10.1097/AOG.0b013e31825a6bc9

Wilkinson, A.P., Wähälä, K., Williamson, G., 2002. Identification and quantification of polyphenol phytoestrogens in foods and human biological fluids. J. Chromatogr. B, Analytical and Biomedical Aspects of Natural Compounds with Estrogenic Activity 777, 93-109. https://doi.org/10.1016/S1570-0232(02)00095-8 
Winter, C.A., Risley, E.A., Nuss, G.W., 1962. Carrageenin-Induced Edema in Hind Paw of the Rat as an Assay for Antiinflammatory Drugs. Proc. Soc. Exp. Biol. Med. 111, 544547. https://doi.org/10.3181/00379727-111-27849

Yıldız, L., Başkan, K.S., Tütem, E., Apak, R., 2008. Combined HPLC-CUPRAC (cupric ion reducing antioxidant capacity) assay of parsley, celery leaves, and nettle. Talanta 77, 304 313. https://doi.org/10.1016/j.talanta.2008.06.028

Yoshikawa, M., Uemura, T., Shimoda, H., Kishi, A., Kawahara, Y., Matsuda, H., 2000. Medicinal Foodstuffs. XVIII. Phytoestrogens from the Aerial Part of Petroselinum crispum MILL. (PARSLEY) and Structures of 6"-Acetylapiin and a New Monoterpene Glycoside, Petroside. Chem. Pharm. Bull. (Tokyo) 48, 1039-1044. https://doi.org/10.1248/cpb.48.1039

Table 1: Retention time and concentration of phenolic compounds of petroselinum sativum

\begin{tabular}{llll}
\hline Phenolic compounds & Formula & $\begin{array}{l}\text { Standards retention } \\
\text { time }(\mathrm{min})\end{array}$ & Concentration $(\mu \mathrm{g} / \mathrm{ml})$ \\
\hline Gallic acid & $\mathrm{C}_{7} \mathrm{H}_{6} \mathrm{O}_{5}$ & 6.645 & 1.21 \\
hydroxytirosol & $\mathrm{C}_{8} \mathrm{H}_{10} \mathrm{O}_{3}$ & 8.5 & 0.19 \\
Ferulic acid & $\mathrm{C}_{10} \mathrm{H}_{10} \mathrm{O}_{4}$ & 21.63 & 6.3 \\
Myricetin & $\mathrm{C}_{14} \mathrm{H}_{28} \mathrm{O}_{2}$ & 22.27 & 0.10 \\
Quercetin & $\mathrm{C}_{15} \mathrm{H}_{10} \mathrm{O}_{7}$ & 23.35 & 0.95 \\
Naringenin & $\mathrm{C}_{15} \mathrm{H}_{12} \mathrm{O}_{5}$ & 24.63 & 0.04 \\
Cinnamic acid & $\mathrm{C}_{9} \mathrm{H}_{2} \mathrm{O}_{2}$ & 25.13 & 0.02 \\
\hline
\end{tabular}

Table 2: Effect of hydro-ethanolic extracts of $P$. Sativum on liver and kidney parameters. Asterisks indicate significant differences at $\mathrm{P}<0.01$ among treatments. The data represents the mean \pm s.e.m. $(n=5)$. 


\begin{tabular}{lclllll}
\hline Treatment & $\begin{array}{l}\text { Dose } \\
(\mathbf{m g} / \mathbf{k g})\end{array}$ & $\begin{array}{l}\text { ASAT } \\
(\mathbf{U} / \mathbf{L})\end{array}$ & $\begin{array}{l}\text { ALAT } \\
(\mathbf{U} / \mathbf{L})\end{array}$ & $\begin{array}{l}\text { ALP } \\
(\mathbf{U} / \mathbf{L})\end{array}$ & $\begin{array}{l}\text { UREA } \\
(\mathbf{m g} / \mathbf{d L})\end{array}$ & $\begin{array}{l}\text { CREA } \\
(\mathbf{m g} / \mathbf{d L})\end{array}$ \\
\hline $\begin{array}{l}\text { Control } \\
\mathbf{N a C l} \mathbf{0 . 9} \%)\end{array}$ & - & $131.6 \pm 17.34$ & $44.6 \pm 0.4$ & $233 \pm 34.82$ & $21.33 \pm 1.49$ & $0.36 \pm 0.04$ \\
$\begin{array}{l}\text { Clomiphene } \\
\text { citrate }\end{array}$ & 308.33 & $157.9 \pm 3.01$ & $64.77 \pm 4.4^{* *}$ & $331.7 \pm 17.17$ & $24.47 \pm 1.91$ & $0.38 \pm 0.02$ \\
$\begin{array}{l}\text { Hydro- } \\
\text { Ethanolic }\end{array}$ & 500 & $119.4 \pm 8.25$ & $43.3 \pm 1.01$ & $207.3 \pm 17.85$ & $27.37 \pm 2.18$ & $0.38 \pm 0.01$ \\
$\begin{array}{l}\text { extract } \\
\text { Hydro- }\end{array}$ & & & & & & \\
$\begin{array}{l}\text { Ethanolic } \\
\text { extract }\end{array}$ & 1000 & $171.6 \pm 4.5$ & $44.07 \pm 2.55$ & $184 \pm 24.79$ & $25.07 \pm 0.93$ & $0.032 \pm 0.05$ \\
\hline
\end{tabular}

Table 3: Effect of the different extracts of Petroselinum Sativum and Indométacin on the oedema induced by carragenin and their percentages of inhibition. Asterisks (*) indicate significant differences at $\mathrm{P}<0.05$ among treatments. The data represents the mean \pm s.e.m. $(n=5)$.

\begin{tabular}{lllllll}
\hline & \multicolumn{5}{c}{ Diameter $(\mathrm{cm})$ and \% of inhibition } \\
\hline Treatment & $\begin{array}{l}\text { Dose } \\
(\mathbf{m g} / \mathbf{k g})\end{array}$ & $\mathbf{0 h}$ & $\mathbf{3 h}$ & $\mathbf{4 h}$ & $\mathbf{5 h}$ & $\mathbf{6 h}$ \\
& & & & & \\
\hline Control (NaCl 0.9\%) & - & $2.37 \pm 0.04$ & $2.72 \pm 0.03$ & $2.71 \pm 0.04$ & $2.62 \pm 0.03$ & $2.62 \pm 0.03$ \\
Indomethacin & 10 & $2.32 \pm 0.03$ & $2.52 \pm 0.03 *$ & $2.46 \pm 0.03 *$ & $2.4 \pm 0.02 *$ & $2.36 \pm 0.03 *$ \\
& & & $50 \%$ & $64 \%$ & $73.33 \%$ & $86.67 \%$ \\
Hydro-ethanolic & 500 & $2.32 \pm 0.03$ & $2.62 \pm 0.03$ & $2.53 \pm 0.03$ & $2.48 \pm 0.03$ & $2.43 \pm 0.03$ \\
extract of P.S & & & $25 \%$ & $47.5 \%$ & $46.67 \%$ & $63.33 \%$ \\
Hydro-ethanolic & 1000 & $2.32 \pm 0.03$ & $2.56 \pm 0.03$ & $2.49 \pm 0.02$ & $2.43 \pm 0.01$ & $2.39 \pm 0.03$ \\
extract of P.S & & & $38 \%$ & $56 \%$ & $62 \%$ & $74 \%$ \\
Polyphenols & 100 & $2.32 \pm 0.03$ & $2.52 \pm 0.03 *$ & $2.46 \pm 0.01 *$ & $2.41 \pm 0.01 *$ & $2.37 \pm 0.03 *$ \\
& & & $48 \%$ & $64 \%$ & $68.67 \%$ & $81.33 \%$ \\
\hline
\end{tabular}




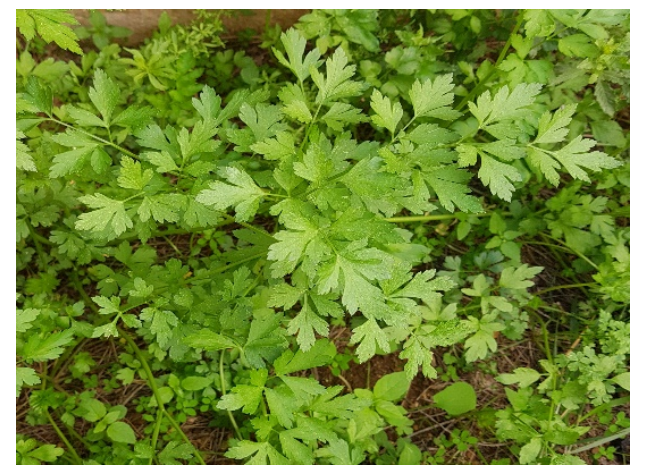

Figure 1: Aerial part of Petroselinum sativum plant 


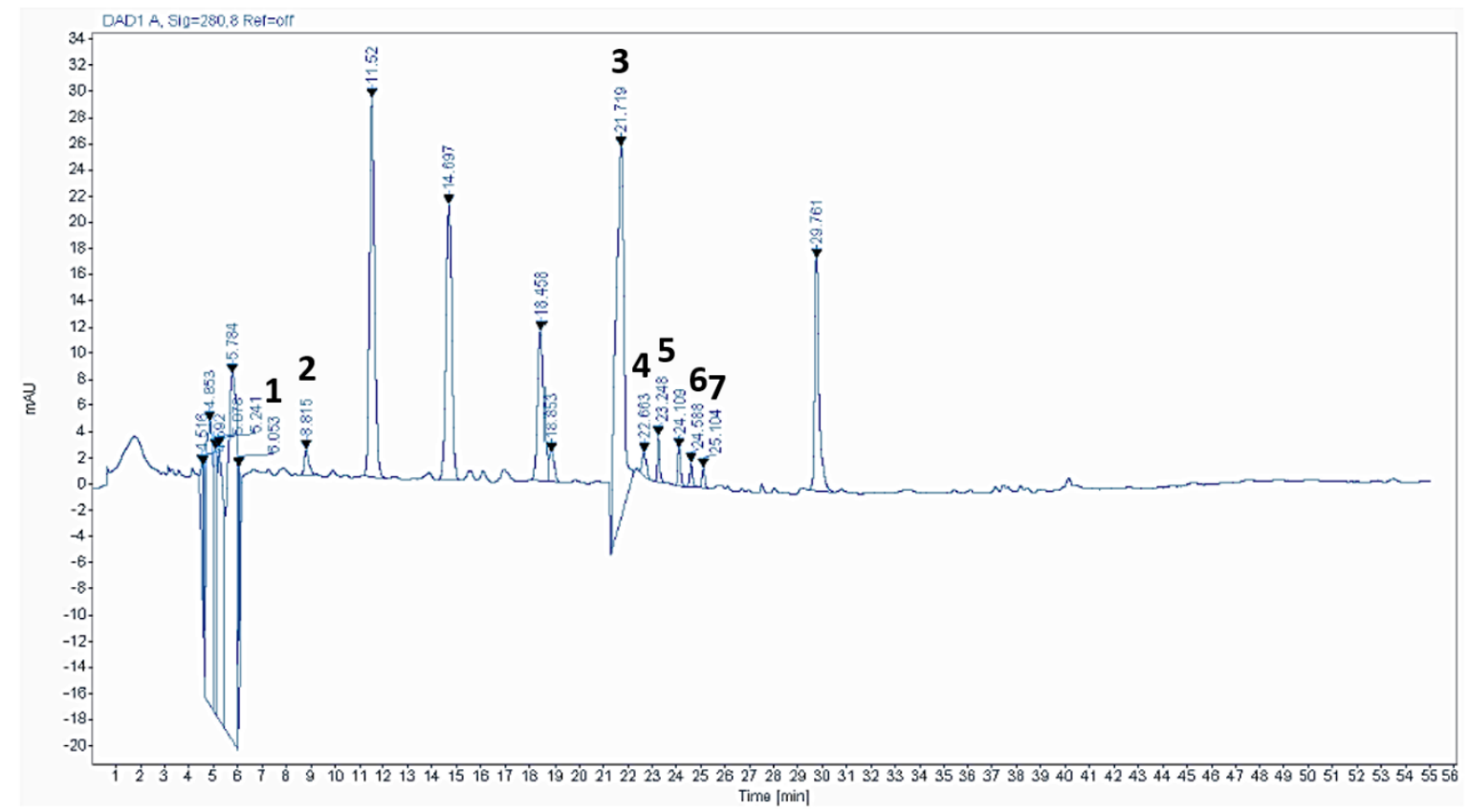

Figure 2: HPLC-DAD chromatogram of Polyphenolic fraction of Petroselinum sativum. (1) Gallic acid, (2) Hydroxytirosol, (3) Ferulic acid, (4) Myricetin, (5) Quercetin, (6) Naringenin, (7) Cinnamic acid. 


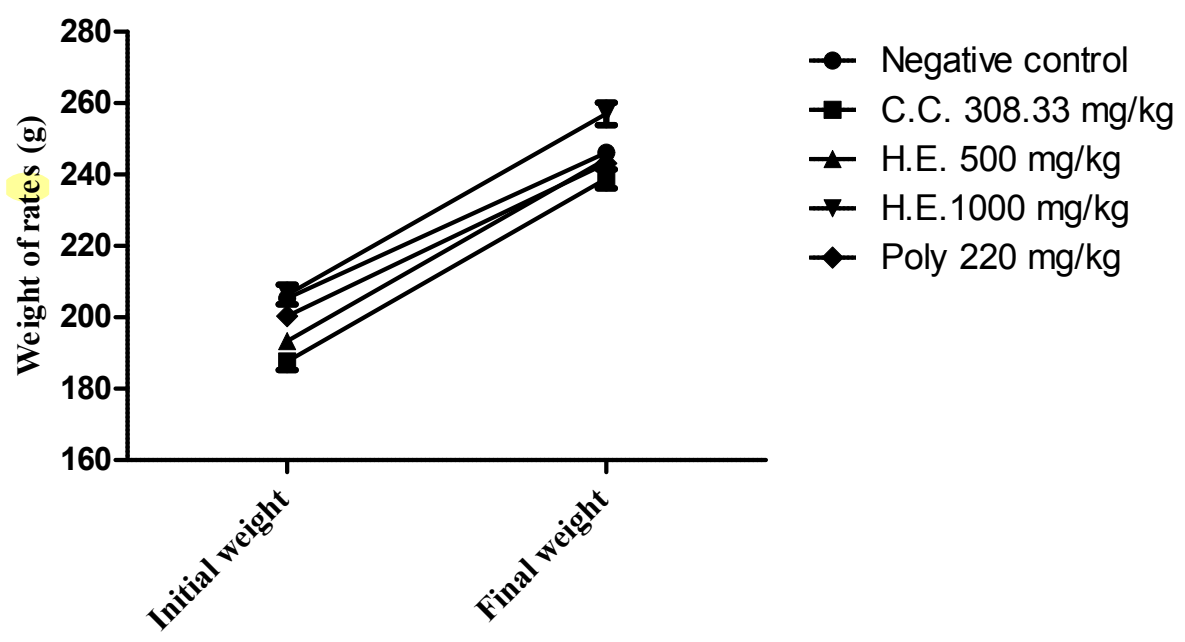

Figure 3: Effect of different treatments on weight gain of female rats before and after 28 days of treatment. Negative control, C.C. (clomiphene Citrate), H.E. (Hydro-Ethanolic extract), Poly (Polyphenols).

(a)

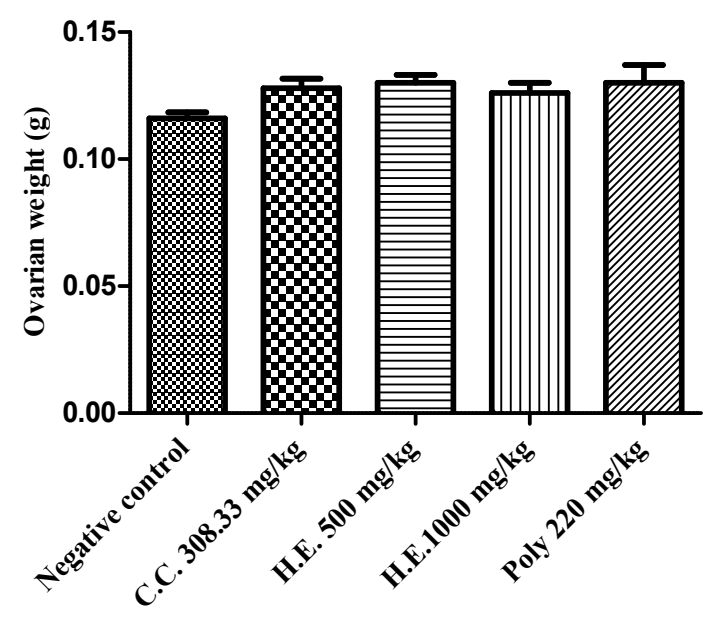

(b)

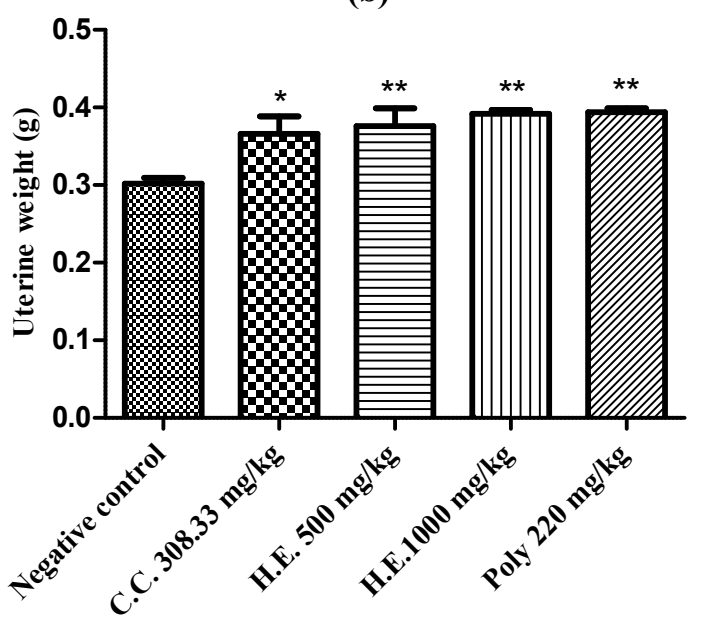

Figure 4: Effect of the hydro-ethanolic extract of Petroselinum S. on (a) ovarian and (b) uterine weights. Asterisks $\left({ }^{*}, * *\right)$ indicate significant differences at $\mathrm{p}<0.05, \mathrm{p}<0.01$ compared to the control group (ANOVA). The data represents the mean \pm s.e.m. $(n=5)$. Negative control, C.C. (clomiphene Citrate), H.E. (Hydro-Ethanolic extract), Poly (Polyphenols). 

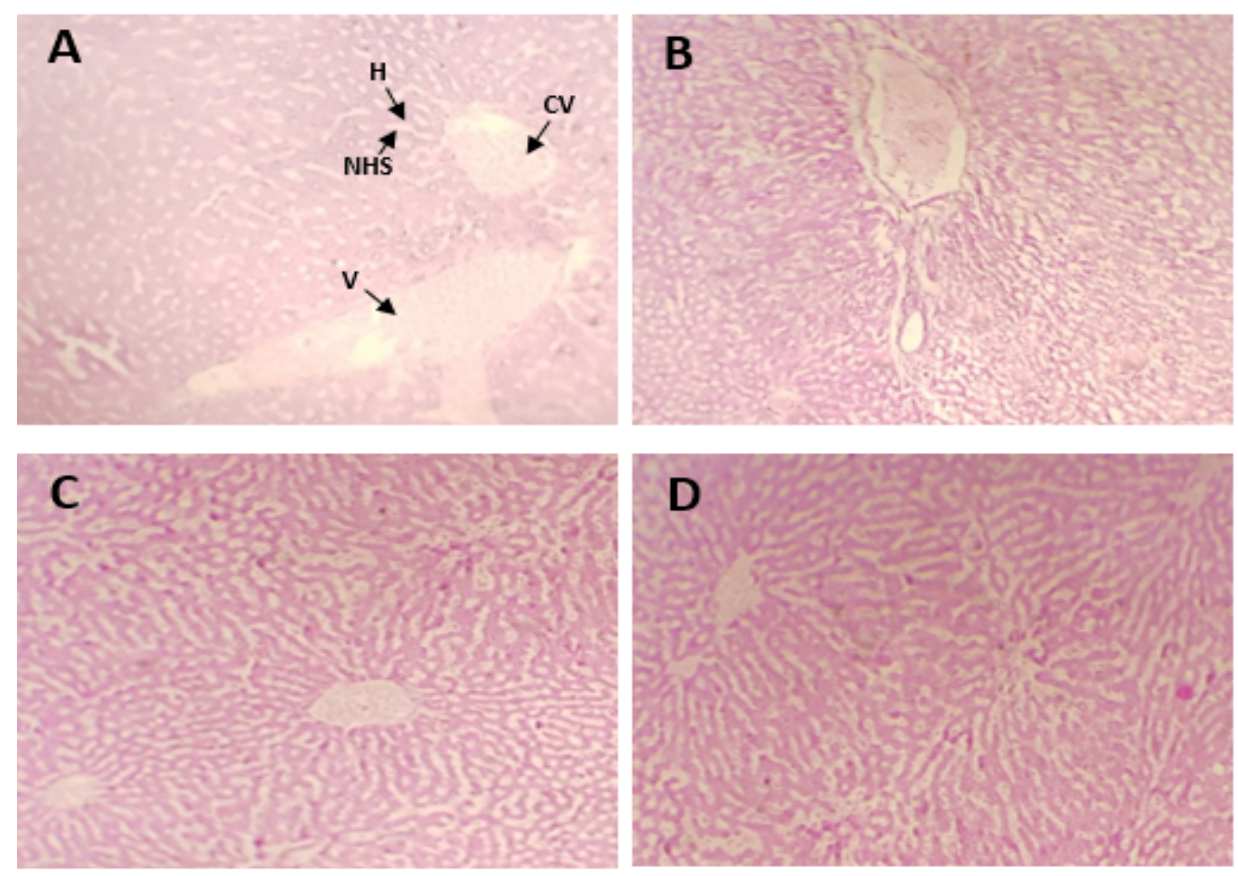

Figure 5: Histological sections (stained with HES $\times 40$ ) of liver: (A) control, (B) hydroethanolic extract at the dose $500 \mathrm{mg} / \mathrm{kg}$, (C) hydro-ethanolic extract at the dose 1000, and (D) polyphenols at the dose $100 \mathrm{mg} / \mathrm{kg}$. $\mathrm{CV}=$ central vein, $\mathrm{V}=$ vein, $\mathrm{H}=$ hepathocytes, $\mathrm{NHS}=$ normal hepatic sinusoids.
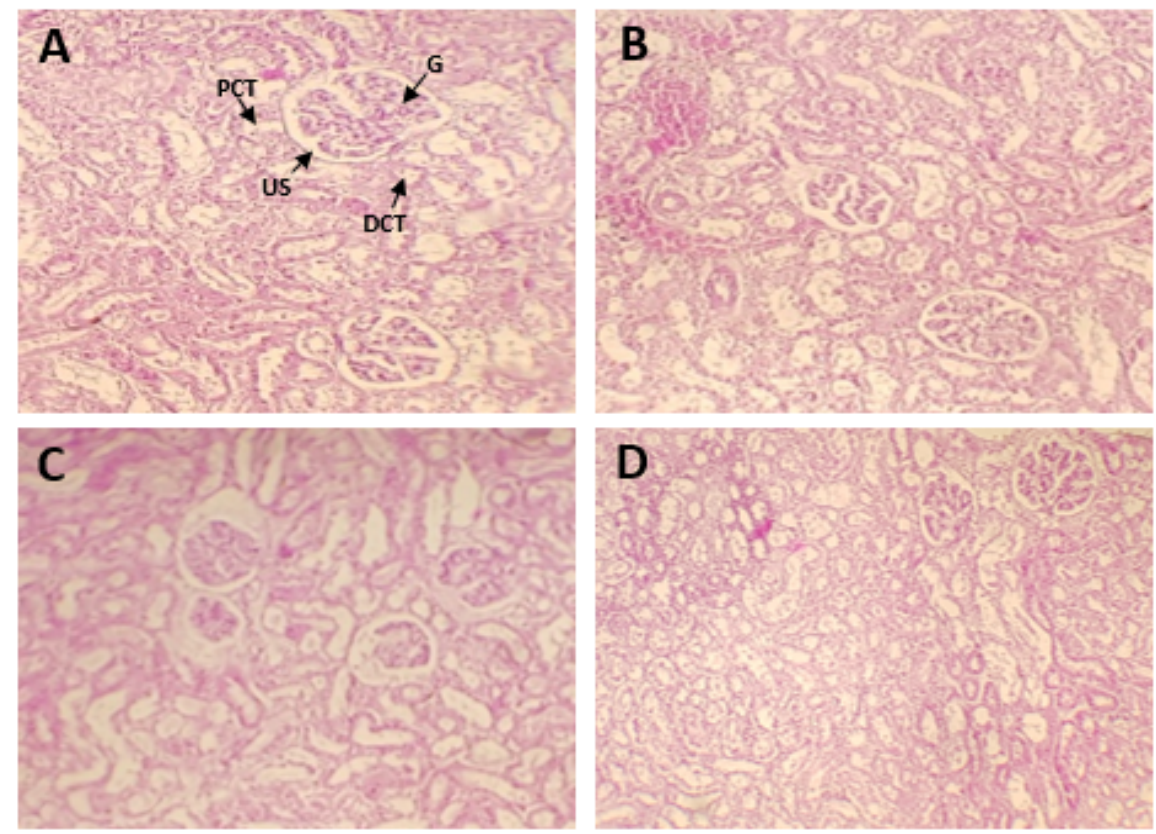
Figure 6: Histological sections (stained with HES $\times 40$ ) of the kidney: (A) control, (B) hydroethanolic extract at the dose $500 \mathrm{mg} / \mathrm{kg}$, (C) hydro-ethanolic extract at the dose 1000, and (D) polyphenols at the dose $100 \mathrm{mg} / \mathrm{kg}$. PCT= proximal convoluted tubule, DCT= distal convoluted tubule, $\mathrm{US}=$ urinary space, $\mathrm{G}=$ glomerulus.

(a)



(b)

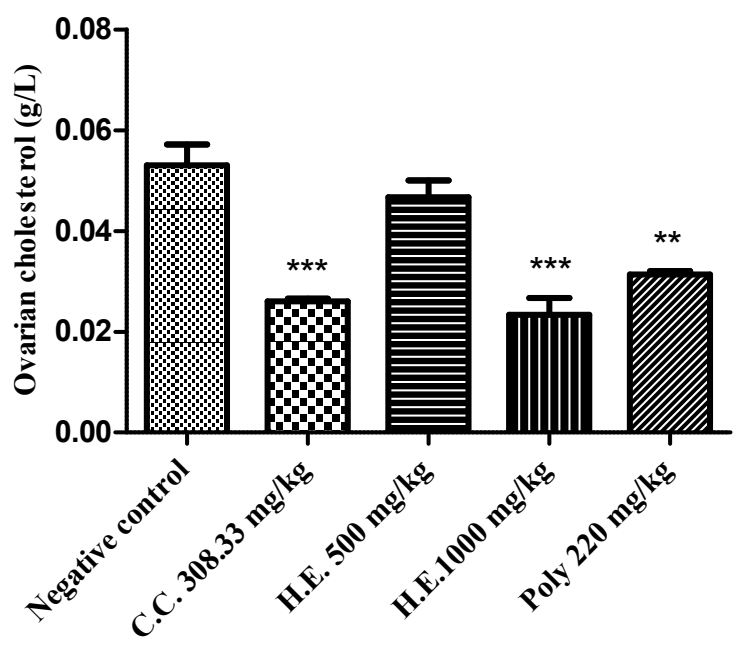

Figure 7: Effect of the different doses of the hydro-ethanolic extract of Petroselinum Sativum on (a) serum and (b) ovarian cholesterol. Asterisks $(*, * *, * * *)$ indicate values differences at $\mathrm{p}<0.05, \mathrm{p}<0.01, \mathrm{p}<0.001$ from those of the control group (ANOVA). Each histogram represents the mean \pm s.e.m of 5 animals $(\mathrm{N}=25)$. Negative control, C.C. (clomiphene Citrate), H.E. (Hydro-Ethanolic extract), Poly (Polyphenol). 


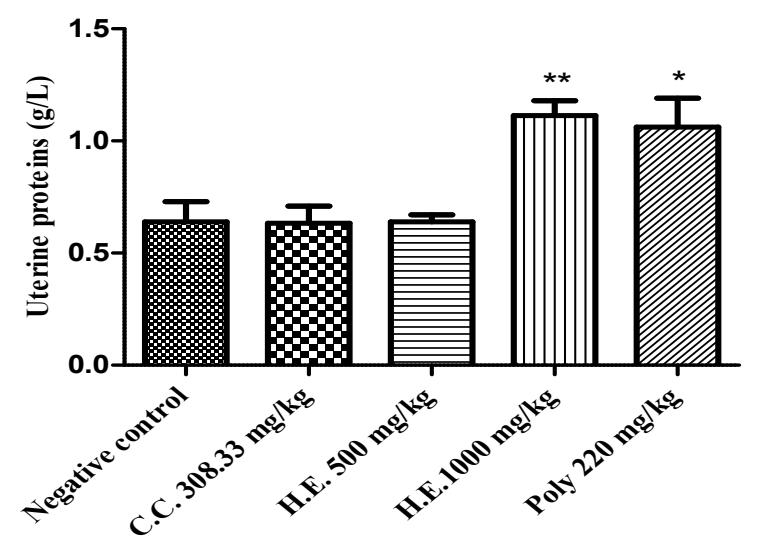

Figure 8: Effect of the different doses of Petroselinum Sativum hydro-ethanolic extract on the uterine proteins. Asterisks $(*, * *)$ indicate values differences at $\mathrm{p}<0.05, \mathrm{p}<0.01$ from those of the control group (ANOVA). Each histogram represents the mean \pm s.e.m. of 5 animals $(\mathrm{N}=25)$. Negative control, C.C. (clomiphene Citrate), H.E. (Hydro-Ethanolic extract), Poly (Polyphenols).

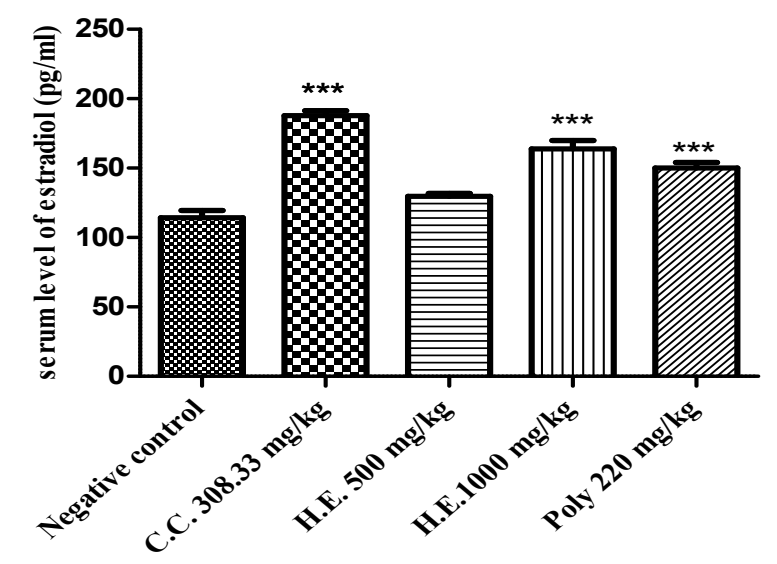

Figure 9: Effect of the different doses of Petroselinum Sativum hydro-ethanolic extract on the concentration of estradiol. Asterisks $(* * *)$ indicate values differences at $\mathrm{p}<0.001$ from those of the control group (ANOVA). Each histogram represents the mean \pm s.e.m of 5 
animals $(\mathrm{N}=25)$. Negative control, C.C. (clomiphene Citrate), H.E. (Hydro-Ethanolic extract), Poly (Polyphenols). 




Figure 1: Aerial part of Petroselinum sativum plant

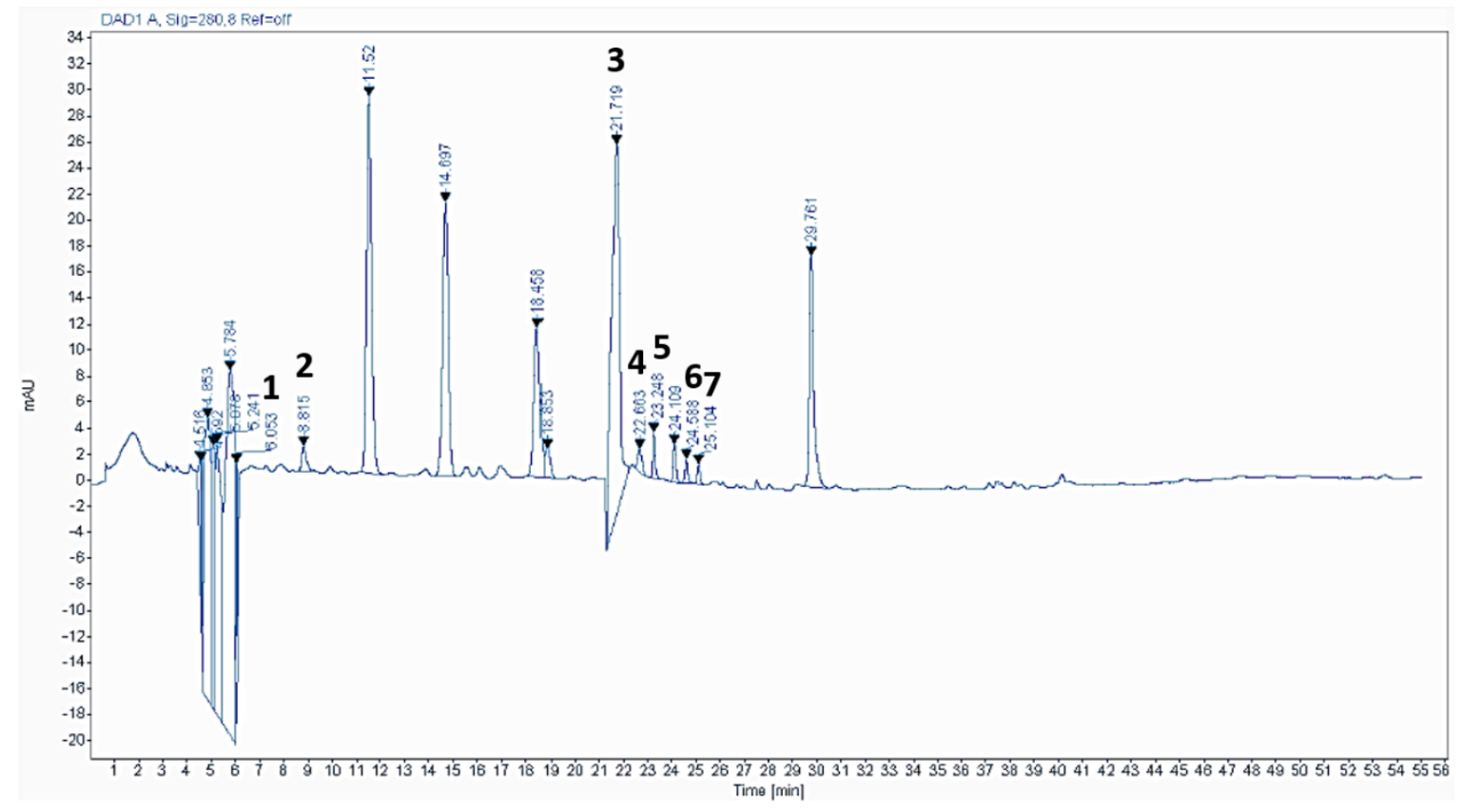

Figure 2: HPLC-DAD chromatogram of Polyphenolic fraction of Petroselinum sativum. (1) Gallic acid, (2) Hydroxytirosol, (3) Ferulic acid, (4) Myricetin, (5) Quercetin, (6) Naringenin, (7) Cinnamic acid. 


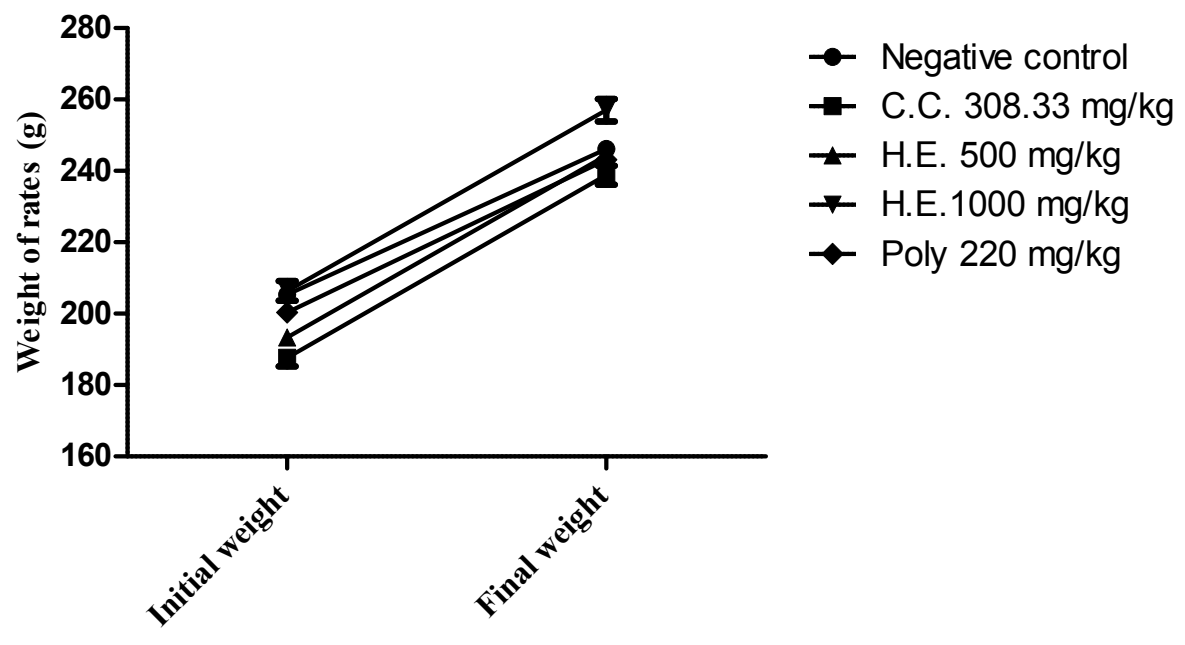

Figure 3: Effect of different treatments on weight gain of female rats before and after 28 days of treatment. Negative control, C.C. (clomiphene Citrate), H.E. (Hydro-Ethanolic extract), Poly (Polyphenols).

(a)

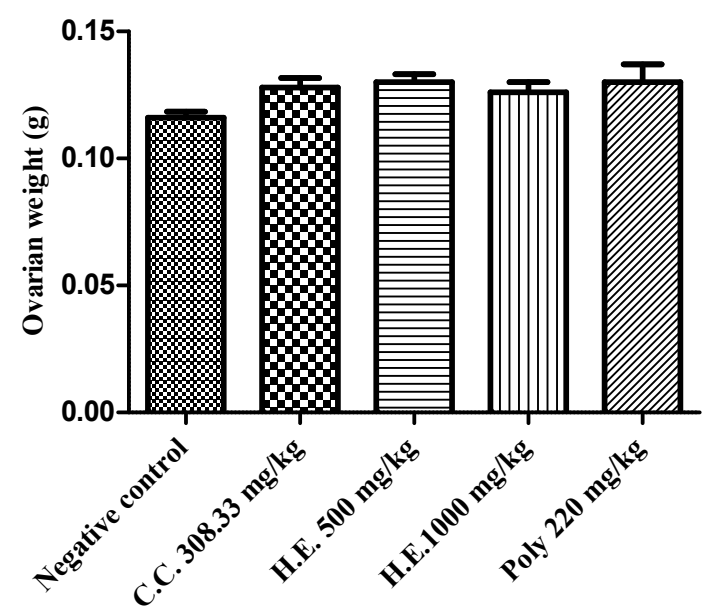

(b)

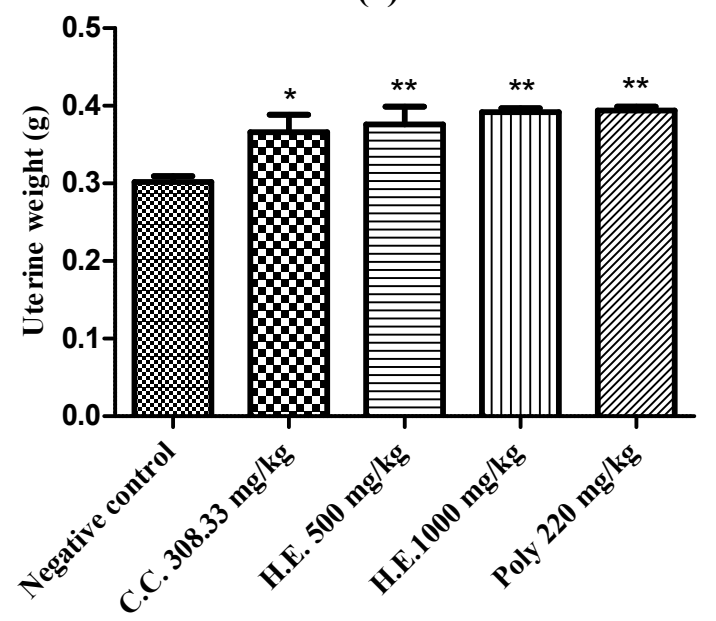

Figure 4: Effect of the hydro-ethanolic extract of Petroselinum S. on (a) ovarian and (b) uterine weights. Asterisks $(*, * *)$ indicate significant differences at $\mathrm{p}<0.05, \mathrm{p}<0.01$ compared to the control group (ANOVA). The data represents the mean \pm s.e.m. $(n=5)$. Negative control, C.C. (clomiphene Citrate), H.E. (Hydro-Ethanolic extract), Poly (Polyphenols). 

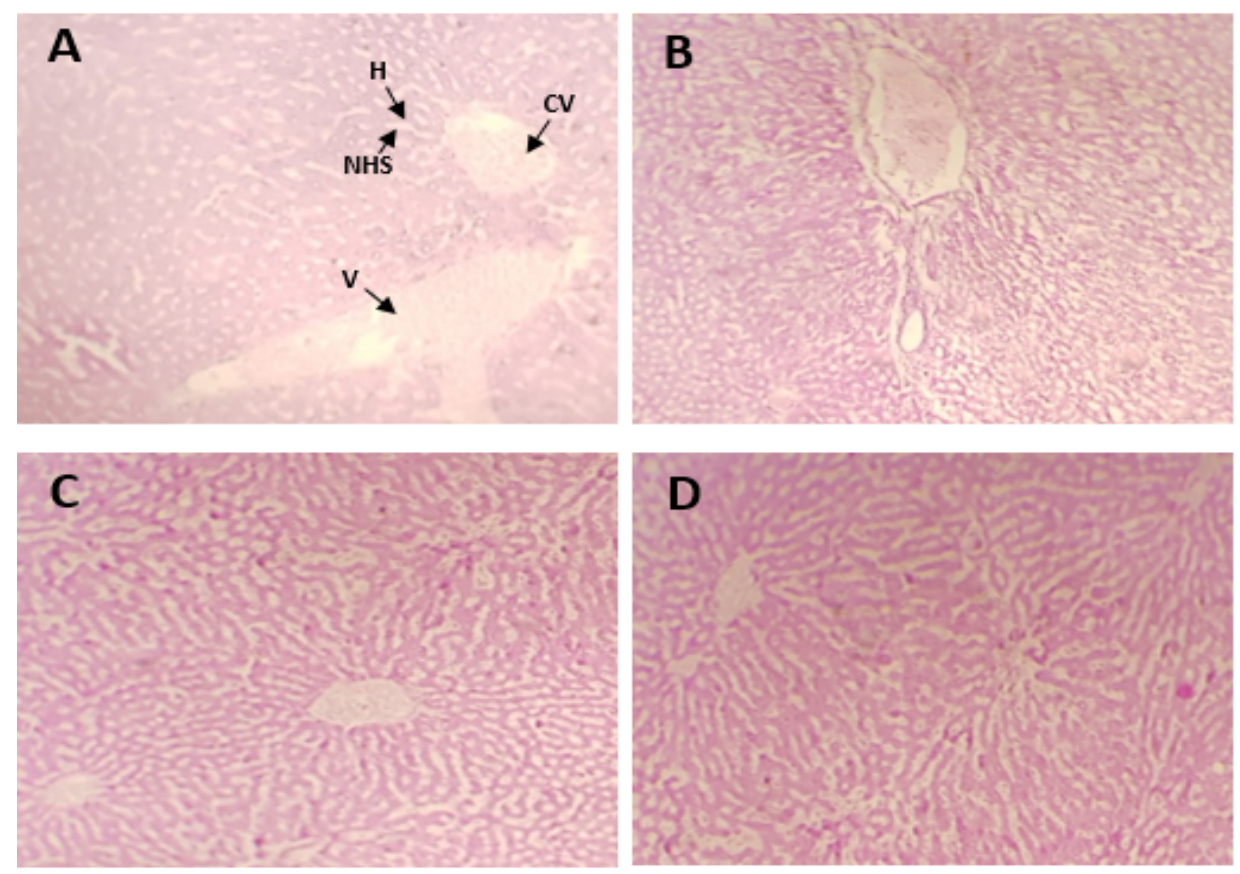

Figure 5: Histological sections (stained with HES $\times 40$ ) of liver: (A) control, (B) hydro-ethanolic extract at the dose $500 \mathrm{mg} / \mathrm{kg}$, (C) hydro-ethanolic extract at the dose 1000, and (D) polyphenols at the dose $100 \mathrm{mg} / \mathrm{kg}$. $\mathrm{CV}=$ central vein, $\mathrm{V}=$ vein, $\mathrm{H}=$ hepathocytes, $\mathrm{NHS}=$ normal hepatic sinusoids.
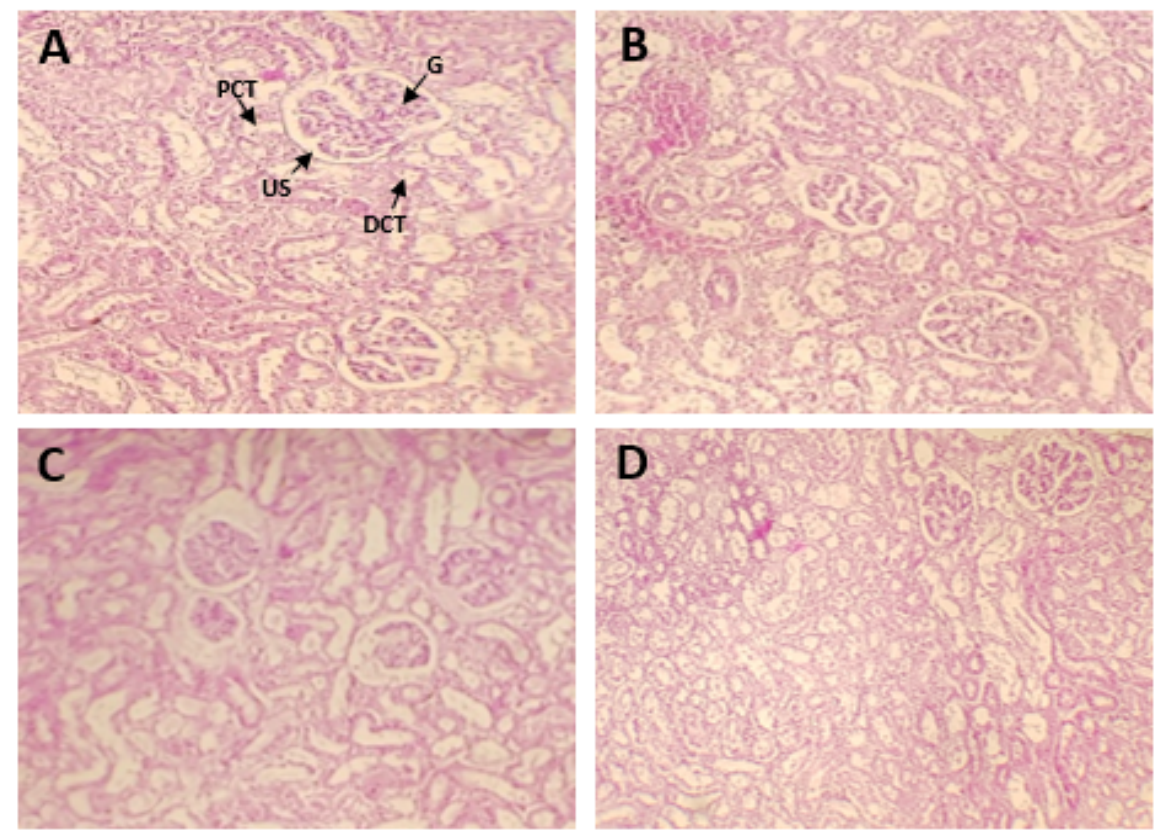

Figure 6: Histological sections (stained with HES $\times 40$ ) of the kidney: (A) control, (B) hydroethanolic extract at the dose $500 \mathrm{mg} / \mathrm{kg}$, (C) hydro-ethanolic extract at the dose 1000, and (D) 
polyphenols at the dose $100 \mathrm{mg} / \mathrm{kg}$. PCT= proximal convoluted tubule, DCT= distal convoluted tubule, $\mathrm{US}=$ urinary space, $\mathrm{G}=$ glomerulus.

(a)

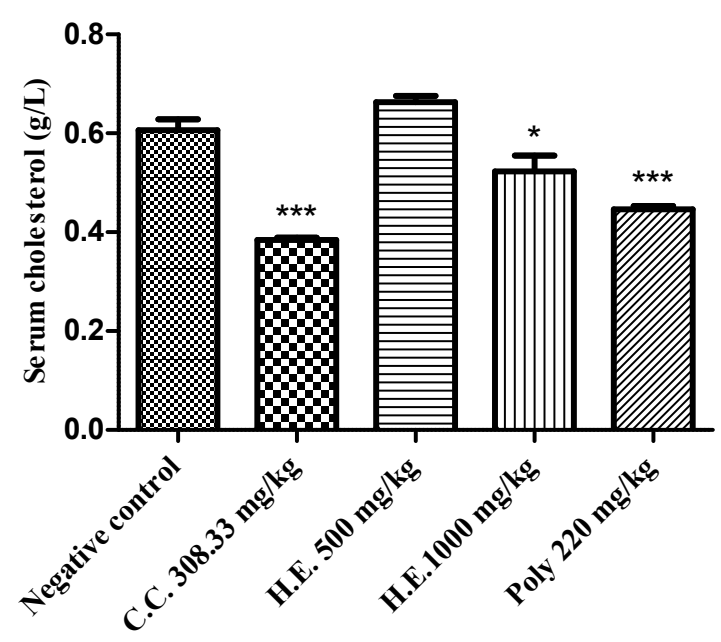

(b)

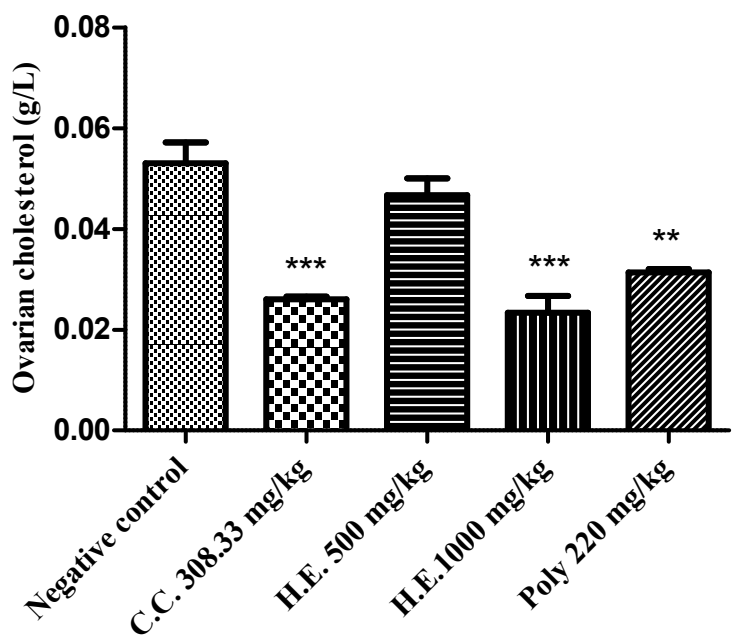

Figure 7: Effect of the different doses of the hydro-ethanolic extract of Petroselinum Sativum on (a) serum and (b) ovarian cholesterol. Asterisks $\left(*,{ }^{* *},{ }^{* * *}\right)$ indicate values differences at $\mathrm{p}<0.05$, $p<0.01, p<0.001$ from those of the control group (ANOVA). Each histogram represents the mean \pm s.e.m of 5 animals $(\mathrm{N}=25)$. Negative control, C.C. (clomiphene Citrate), H.E. (Hydro-Ethanolic extract), Poly (Polyphenol).

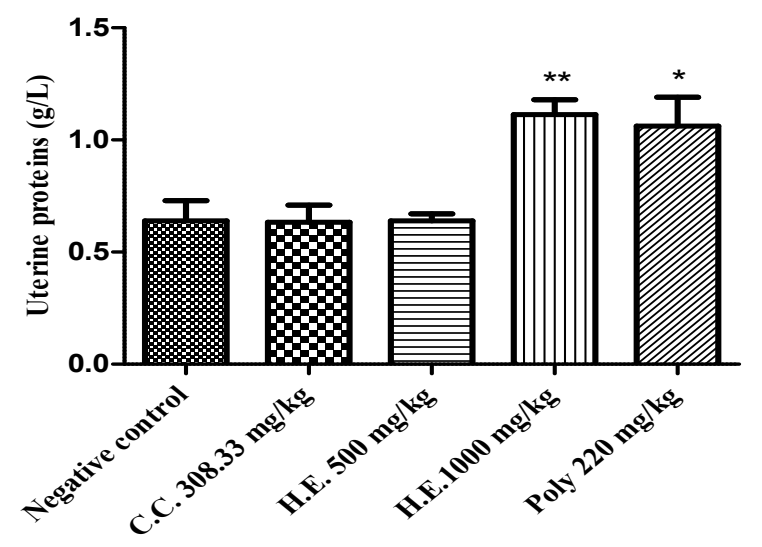


Figure 8: Effect of the different doses of Petroselinum Sativum hydro-ethanolic extract on the uterine proteins. Asterisks $(*, * *)$ indicate values differences at $\mathrm{p}<0.05, \mathrm{p}<0.01$ from those of the control group (ANOVA). Each histogram represents the mean \pm s.e.m. of 5 animals $(\mathrm{N}=25)$. Negative control, C.C. (clomiphene Citrate), H.E. (Hydro-Ethanolic extract), Poly (Polyphenols).

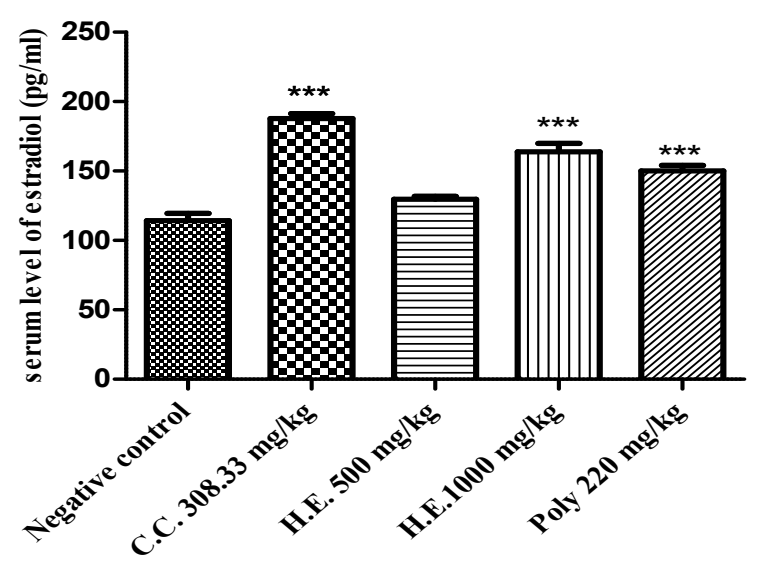

Figure 9: Effect of the different doses of Petroselinum Sativum hydro-ethanolic extract on the concentration of estradiol. Asterisks $(* * *)$ indicate values differences at $p<0.001$ from those of the control group (ANOVA). Each histogram represents the mean \pm s.e.m of 5 animals $(\mathrm{N}=25)$. Negative control, C.C. (clomiphene Citrate), H.E. (Hydro-Ethanolic extract), Poly (Polyphenols). 


\section{CONFLICT OF INTERESTS}

The authors have not declared any conflict of interests. 